\title{
Hydrologic impact of climate change on Murray-Hotham catchment of Western Australia: a projection of rainfall-runoff for future water resources planning
}

\author{
S. A. Islam ${ }^{1,2}$, M. A. Bari' ${ }^{2}$, and A. H. M. F. Anwar ${ }^{1}$ \\ ${ }^{1}$ Department of Civil Engineering, School of Civil and Mechanical Engineering, Curtin University, Perth, Western Australia \\ ${ }^{2}$ Bureau of Meteorology, Australian Government, Perth, Australia
}

Correspondence to: S. A. Islam (s.islam@bom.gov.au)

Received: 21 August 2013 - Published in Hydrol. Earth Syst. Sci. Discuss.: 2 October 2013

Revised: 13 March 2014 - Accepted: 15 July 2014 - Published: 12 September 2014

\begin{abstract}
Reduction of rainfall and runoff in recent years across southwest Western Australia (SWWA) has attracted attention to the climate change impact on water resources and water availability in this region. In this paper, the hydrologic impact of climate change on the Murray-Hotham catchment in SWWA has been investigated using a multi-model ensemble approach through projection of rainfall and runoff for the periods mid (2046-2065) and late (2081-2100) this century. The Land Use Change Incorporated Catchment (LUCICAT) model was used for hydrologic modelling. Model calibration was performed using $(5 \mathrm{~km})$ grid rainfall data from the Australian Water Availability Project (AWAP). Downscaled and bias-corrected rainfall data from 11 general circulation models (GCMs) for Intergovernmental Panel on Climate Change (IPCC) emission scenarios A2 and B1 was used in LUCICAT model to derive rainfall and runoff scenarios for 20462065 (mid this century) and 2081-2100 (late this century). The results of the climate scenarios were compared with observed past (1961-1980) climate. The mean annual rainfall averaged over the catchment during recent time (19812000) was reduced by $2.3 \%$ with respect to the observed past (1961-1980) and the resulting runoff reduction was found to be $14 \%$. Compared to the past, the mean annual rainfall reductions, averaged over 11 ensembles and over the period for the catchment for A2 scenario are 13.6 and $23.6 \%$ for mid and late this century respectively while the corresponding runoff reductions are 36 and $74 \%$. For B1 scenario, the rainfall reductions were 11.9 and $11.6 \%$ for mid and late this century and the corresponding runoff reductions were 31 and $38 \%$. Spatial distribution of rainfall and runoff changes
\end{abstract}

showed that the rate of changes were higher in high rainfall areas compared to low rainfall areas. Temporal distribution of rainfall and runoff indicate that high rainfall events in the catchment reduced significantly and further reductions are projected, resulting in significant runoff reductions. A catchment scenario map has been developed by plotting decadal runoff reduction against corresponding rainfall reduction at four gauging stations for the observed and projected periods. This could be useful for planning future water resources in the catchment. Projection of rainfall and runoff made based on the GCMs varied significantly for the time periods and emission scenarios. Hence, the considerable uncertainty involved in this study though ensemble mean was used to explain the findings.

\section{Introduction}

Water is the most precious resources in Western Australia and its economic, social and environmental value is increasing day by day (DoW, 2008). Since the late 1970s, southwest Western Australia (SWWA) has experienced declining rainfall and runoff, which is widely acknowledged and reported in many researches (Bari and Ruprecht, 2003, Li et al., 2005; Joyce, 2007; CSIRO, 2009; Petrone et al., 2010; DoW, 2010; and Anwar et al., 2011). In the third assessment report, the Intergovernmental Panel on Climate Change (IPCC) identified Perth as one of the most vulnerable areas which will experience a reduction in surface water supplies in the future (IPCC, 2001). The same issue is also acknowledged 
in local research (Ryan and Hope, 2006) and policy initiatives (WA, 2003). Perth's surface water catchments are located in the Darling Range in SWWA. The winter rainfall in the Darling Range has decreased by up to $20 \%$ over the past 30 years, resulting in a $40 \%$ or more reduction in runoff to reservoirs supplying water to Perth (IOCI, 2002; Bari and Ruprecht, 2003; Water Corporation, 2009). On the other hand, the population of Western Australia has been increasing and is predicted to rise from 1.1 to 3.1 million by 2050 for SWWA (Charles et al., 2007). Hence, with a trend of below-average rainfall for the last several decades, a recent succession of dry years and an increasing trend of population growth have focused the attention of scientists and policy makers on the issue of availability and reliability of water resources in SWWA. In this study, climate change impact on rainfall and runoff during mid and late this century in the Murray-Hotham catchment (Fig. 1) of SWWA has been assessed for $\mathrm{A} 2$ and $\mathrm{B} 1$ emission scenarios.

General circulation models (GCMs) can simulate reliably most of the important features of global climate at the large scale (Zorita and Storch, 1999) and are still the most important source of generating future climate scenarios based on emission scenarios. Ranged from warmest to coolest, the emission scenarios presented in the IPCC Special Report on Emission Scenarios (SRES) are A1FI, A2, A1B, B2, A1T, and B1 (IPCC, 2000). Though climate change impact studies on the hydrologic regime were relatively rare until the last decade (Dibike and Coulibaly, 2005), there have since been numerous studies carried out in a wide variety of environments around the world (Kundzewicz et al., 2007; Bates et al., 2008). As hydrologists and decision makers are mostly interested in evaluating climate change impact at the individual catchment and stream level, with a huge number of downscaling works from climate model output (Flower and Wilby, 2007), the number of climate change impact studies at the catchment scale is increasing. It appears that all the climate change impact studies are carried out through the downscaling of climate model scenario(s) which are subsequently used as an input to calibrate a hydrologic model(s) for hydrologic output. In reality, every study is unique based on the selection of climate model(s), downscaling technique(s), hydrologic model(s), environment, objective of the study, timescale and emission scenario(s). For example Cherkauer and Sinha (2010) studied the impact of projected climate (early 2010-2039, mid-century 2040-2069 and late century 2070-2099) in the Lake Michigan region using IPCC Fourth Assessment Report (AR4) data. They produced maps of surface runoff and baseflow, and presented hydrologic aspects of the distribution of the daily flow and seasonal variation of flows. Shrestha et al. (2012) investigated climate change effects on runoff, snowmelt and discharge peaks in two representative sub-catchments of the Red and Assiniboine basins in the Lake Winnipeg watershed (dominated by spring snowmelt runoff), Canada, for a 21 -year baseline (1980-2000) and future (2042-2062) climate using climate forcing derived from three regional climate models (RCMs). Fujihara et al. (2008) explored the potential impacts of climate change on the hydrology and water resources of the Seyhan River basin in Turkey using dynamically downscaled data of two GCMs, MRI-CGCM2 (Yukimoto et al., 2001) and MIROC (K-1 Model Developers, 2004), under the A2 scenario for two 10-year time slices, the present (1990s) and the future (2070s). They found that water use and management will play more important roles than climate change in controlling future water resources in the Seyhan River basin. For the Okanagan Basin, a snow-driven semi-arid basin located in the southern interior region of British Columbia, Merritt et al. (2006) generated climate scenarios using three GCMs (CGCM2, CSIROMk2, and HadCM3) for high (A2) and low (B2) emission scenarios for the periods 2010-2039 (2020s), 2040-2069 (2050s) and 2070-2099 (2080s). Findings include a precipitation increase of the order of 5-20\% by the 2050s in the Okanagan Basin (Merritt et al., 2006). Christensen and Lettenmaier (2007) assessed the impact of climate change on the hydrology and water resources of the Colorado River basin using a multi-model ensemble approach with downscaled and bias-corrected output from 11 GCMs. They used each of the 11 GCMs to downscale climate scenarios (ensembles) to the variable infiltration capacity (VIC) macro-scale hydrology model for the two emission scenarios A2 and B1. Studies on the hydrological impact of climate change are continuing around the world (Nóbrega et al., 2011; Hughes et al., 2011; and Mahat and Anderson, 2013). Results of these impact studies on rainfall and runoff changes in the catchments vary widely in sign and magnitude and each study appears unique in nature. Therefore, the findings of one study cannot be replicated in another catchment and the need for climate change impact studies for individual catchments appears to be ever-increasing.

In Australia, Charles et al. (2007) investigated rainfall and runoff change during mid-century (2035-2064) along with quantifying the uncertainty involved in downscaling multisite daily precipitation across SWWA using multiple GCMs for the A2 emission scenario. The annual rainfall decrease during mid-century for two GCMs, CSIRO Mk3 and CSIRO Conformal Cubic Atmospheric Model (CCAM), was found to be $12-14 \%$ and the resulting decrease of runoff was found to be $30-44 \%$. Bari et al. (2010) examined long-term water availability in the Serpentine catchment of SWWA through future (2046-2065 and 2081-2100) rainfall-runoff projection, using the rainfall data from 11 GCMs for the emission scenarios A2 and B1. The findings show that nearly all GCMs projected rainfall reductions by mid and late this century (Bari et al., 2010). Other studies assessing the impact of climate change on water resources and catchment hydrology in Australia include Ritchie et al. (2004), Bari et al. (2005) and Islam et al. (2011). However, most of these studies are focused on specific climate scenarios (Bari et al., 2010). In another study, Chiew et al. (1995) simulated the impact of climate change on runoff and soil moisture in 28 
Australian catchments for the years 2030 and 2070 using results from five GCMs applied to a hydrologic daily rainfallrunoff model. They found runoff changes up to $\pm 50 \%$ near the western coast of Australia during 2030, compared to the runoff during 1974-1986. Joyce (2007) examined future (2035-2064) climate variability and hydrologic impact of climate change on the Murray-Hotham catchment using the CSIRO CCAM run for A2 scenario. She found that a $13 \%$ decrease of mean annual rainfall is projected with a corresponding $49 \%$ decrease in stream flow during 2035-2064, compared to the baseline period 1975-2004.

With a recent trend of drying climate in SWWA, understanding future climate change impact is a necessity, particularly for planning future water resources. Water agencies in Western Australia are shifting their policy from surface water dependence to more reliance on groundwater and desalination. For planning water resources, water resources managers and policy makers need to answer questions like "Will the declining trend of rainfall and runoff in Perth's surface water catchments continue during mid and late this century?" Limited study has been carried out in the SWWA using multiple GCM data for different climate scenarios for longer periods. The literature suggests that climate change and its impact vary widely geographically, from continent to continent, country to country and even catchment to catchment. In addition, though GCMs are the best available tools for generating climate change scenarios based on emission scenarios, the results of the GCMs vary considerably. Selection of downscaling methods and hydrologic model also affects the outcome of climate change impact studies, though GCMs are still the largest source of uncertainty. Thus, to develop a range of plausible scenarios of future impact, drawing multiple trajectories using multiple GCM output is a recent trend in climate change impact study. Hence, there is a prevailing research gap regarding the probable climate change impact on water resource catchments in SWWA addressing the need of water resources planning, particularly using multiple climate model scenarios.

Most of Perth's surface water supply dams are located along a line from Mundaring (about $90 \mathrm{~km}$ east of Perth) to Wellington (about $40 \mathrm{~km}$ east of Bunbury), north to south (Fig. 1). The Murray River basin lies in the middle of this line and there are three dams located in the lower areas of the basin - Serpentine, North Dandalup and South Dandalup. The Murray-Hotham catchment is located in upper areas of the Murray River basin (Fig. 1) and has been selected for this study as a representative catchment of Perth's surface water supply catchments. The aim of this study is to investigate the climate change impact on rainfall and runoff across the Murray-Hotham catchment during mid (2055) and late this century (2090) using 11 climate model data sets reported in IPCC AR4 (IPCC, 2007) for A2 and B1 emission scenarios. Preliminary findings of this research focusing on stream flow reduction has been presented at a conference (Anwar et al., 2011). In this paper, spatial and temporal variability along with probability of exceedance of observed and projected rainfall and runoff are presented. In addition, a catchment scenario map has been developed plotting decadal rainfall and runoff change for observed and projected periods, which can be used for future water resources planning.

\section{The Murray-Hotham catchment}

The Murray River catchment, with an area of $6736 \mathrm{~km}^{2}$, lies within the Murray River basin and the Peel-Harvey subregion, around $110 \mathrm{~km}$ southwest of Perth in Western Australia (Fig. 1). To distinguish this study area from the wellknown Murray-Darling catchment in eastern Australia, it is referred to as the Murray-Hotham catchment in reference to the two major rivers in the catchment. Geologically, the catchment is located in the Darling Plateau, the surface of Yilgarn Block. With an average elevation of about $300 \mathrm{~m}$, the plateau is veneered with laterite of Tertiary age formed through weathering of the basement rocks, overlaying the Archaean granite and metamorphic rocks (DoW, 2011). The climate of the catchment is temperate based on the Köppen classification system (Stern et al., 2000) with hot dry summers and cool winters with most of the rainfall (around $75 \%$ ) occurring during winter between May and September. Observed mean annual rainfall varied across the catchment from east to west, low $(400 \mathrm{~mm})$ to high $(1100 \mathrm{~mm})$ with a gradual increase. Mean annual rainfall above $700 \mathrm{~mm}$ is mostly in the lower end (west) of the catchment and very high rainfall ( $900 \mathrm{~mm}$ and above) is very much concentrated in the bottom end of the catchment. Generally, summer rainfall is due to tropical storms and winter rainfall is predominantly due to frontal systems from the southwest (Ruprecht et al., 2005). Mean annual evaporation ranges from $1600 \mathrm{~mm}$ towards the southwest to $1800 \mathrm{~mm}$ in the northeast corner of the basin (Mayer et al., 2005). Mean annual rainfall and runoff of contributing catchments at the gauging stations are presented in Table 1. The Murray River is one of the largest rivers in terms of flow volume in SWWA which begins as the Hotham and Williams River systems and drains into the Indian Ocean via the Peel Inlet near Mandurah. Murray is the only free-flowing river (devoid of dam) in the northern Jarrah Forest in Western Australia. Passing through the hilly country, the rivers deepen and unite to form the Murray at south of Boddington, then passing through the Darling Range and onto the coastal plain (Pen and Hutchison, 1999). Above the Baden Powell Spout on the Murray River, about $60 \%$ of the catchment has been cleared. Though the valleys of the catchment were cleared from the 1980s onward, broad acre clearing began in 1950s (PWD, 1984) and the cleared area is used for sheep and cattle grazing with some cereal production (Beeston et al., 2002). Recent vegetation in the catchment is mostly Eucalyptus woodland from Marradong Road Bridge eastwards, and the remaining part is Eucalyptus open forest (DoW, 2011). 


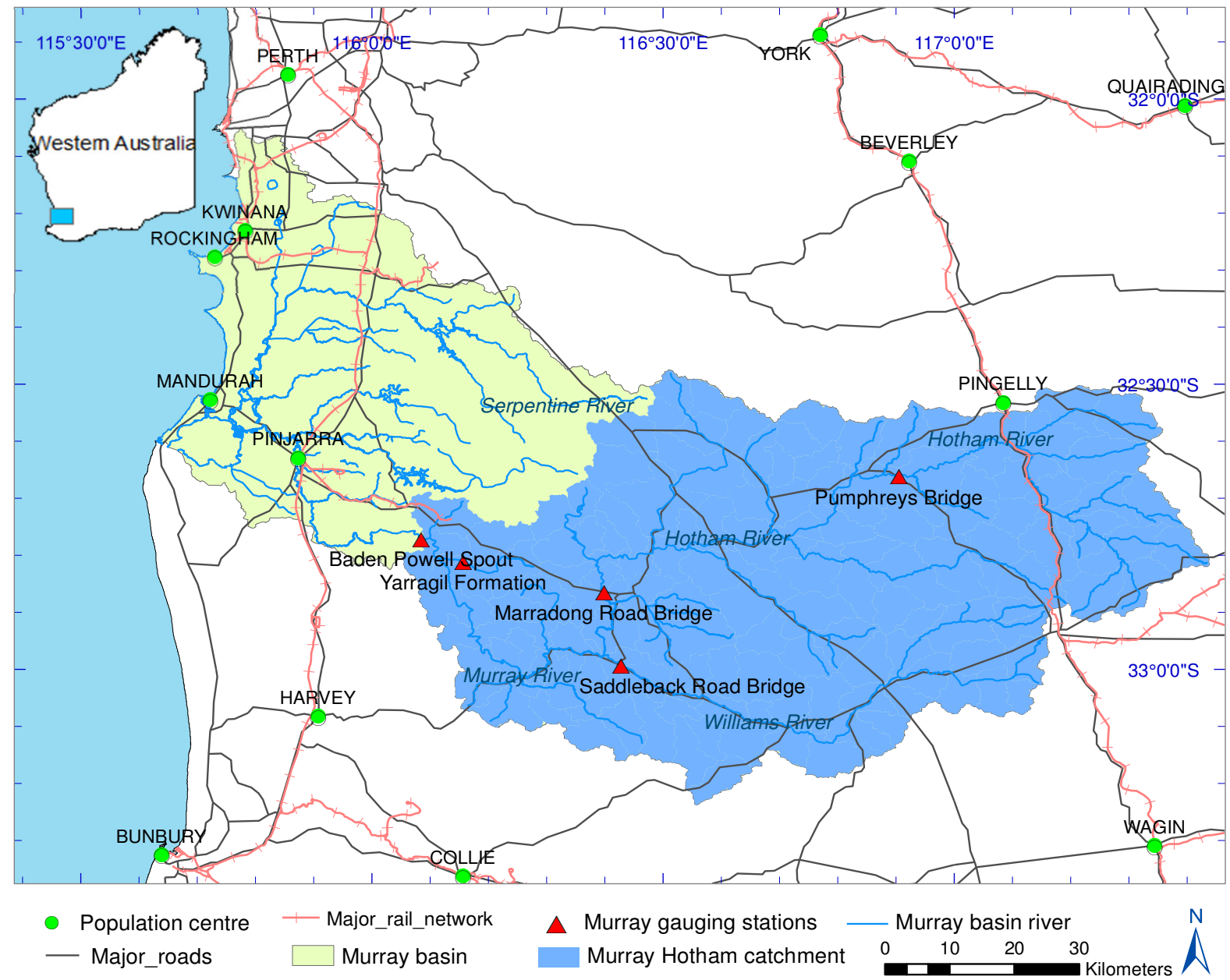

Figure 1. Murray-Hotham catchment of Western Australia with major rivers and gauging stations in the study area.

\section{Data and methods}

\subsection{General circulation models and climate change scenarios}

Eleven GCMs were selected based on the available literatures, the IPCC Fourth Assessment Report (AR4; IPCC, 2007), and major climate modelling centres worldwide. These models provide consistent runs for the future simulation period (2000-2100) and the 20th century (1961-2000) for the emission scenarios A2 and B1 (Christensen and Lattenmaier, 2007). These models are also found to be suitable for the Australian climate as given in Bari et al. (2010). The selected GCMs are listed in Table 2.

The six plausible emission scenarios generated by the IPCC in its Special Report on Emission Scenarios (SRES) for future greenhouse gas emissions are: A1FI, A1B, A1T, $\mathrm{A} 2$, B1, and B2. In terms of global greenhouse gas emissions and global temperature increase, the scenarios can be arranged from warmest to coolest as A1FI, A2, A1B, B2, A1T, and B1. According to the IPCC SRES (IPCC, 2000),
A2 represents a very heterogeneous world with high population growth, slow economic development and slow technological change. On the other hand, B1 describes a convergent world with a global population that peaks at mid-century, very rapid economic growth, rapid introduction of new and more efficient technologies. In terms of $\mathrm{CO}_{2}$ emission level at the end of this century, global average $\mathrm{CO}_{2}$ concentrations will reach to $850 \mathrm{ppm}$ under A2 scenario. Under B1 scenario, $\mathrm{CO}_{2}$ concentrations will initially increase at nearly similar rate as A2 scenario, but will level off at around mid-century and end at 550 ppm (IPCC, 2000). The scenarios A2 and B1 are selected for this study as these are widely simulated in all models and represent a plausible range of conditions over this century (Christetensen and Lattenmaier, 2007).

\subsection{The LUCICAT hydrologic model}

The LUCICAT is a semi-distributed hydrologic model that divides a large catchment into small response units (RUs) (Bari and Smettem, 2003). The RUs are the fundamental "building blocks" that can account for varying spatial 
Table 1. The gauging stations of Murray-Hotham catchment with mean annual rainfall and runoff (during 1961-2000 and 1961-1970) of corresponding contributing catchment at the gauging stations. Runoff figures in parentheses are values in mm. Runoff figure at Pumphreys Bridge is the mean during 1996-2009 for which observed flow data are available.

\begin{tabular}{lrrrrrrr}
\hline $\begin{array}{l}\text { Station } \\
\text { name }\end{array}$ & $\begin{array}{r}\text { Gauge } \\
\text { number }\end{array}$ & $\begin{array}{r}\text { Catchment } \\
\text { area } \\
\left(\mathrm{km}^{2}\right)\end{array}$ & $\begin{array}{r}\text { Mean annual } \\
\text { rainfall }(\mathrm{mm}) \\
(1961-2000)\end{array}$ & $\begin{array}{r}\text { Mean annual } \\
\text { runoff (GL) } \\
(1961-2000)\end{array}$ & $\begin{array}{r}\text { Mean annual } \\
\text { rainfall (mm) } \\
(1961-1970)\end{array}$ & $\begin{array}{r}\text { Mean annual } \\
\text { runoff (GL) } \\
(1961-1970)\end{array}$ & $\begin{array}{r}\text { Station } \\
\text { commencement } \\
\text { year }\end{array}$ \\
\hline Pumphreys Bridge & 614105 & 1306 & 441 & $17(13)$ & 469 & - & 1996 \\
Marradong Road Bridge & 614224 & 3967 & 547 & $129(33)$ & 586 & 163 & 1965 \\
Saddleback Road Bridge & 614196 & 1408 & 564 & $76(54)$ & 605 & 106 \\
Yarragil Formation & 614044 & 73 & 964 & $3(41)$ & 1050 & 6 & 1966 \\
Baden Powell Water Spout & 614006 & 6736 & 616 & $285(42)$ & 663 & 401 & 1951 \\
\hline
\end{tabular}

Table 2. List of GCMs used in this study to produce rainfall-runoff scenarios during mid and late this century.

\begin{tabular}{llll}
\hline Abbreviation & Modelling group/country & IPCC Model ID & Reference \\
\hline CSIRO & CSIRO Atmospheric Research, Australia & CSIRO-MK3.0 & Gordon et al. (2002) \\
CSIRO2 & CSIRO Atmospheric Research, Australia & CSIRO-MK3.5 & Gordon et al. (2010) \\
GFDL1 & Geophysical Fluid Dynamics Laboratory, USA & GFDL-CM2.0 & Delworth et al. (2006) \\
GFDL2 & Geophysical Fluid Dynamics Laboratory, USA & GFDL-CM2.1 & Delworth et al. (2006) \\
GISS & Goddard Institute for Space Studies, USA & GISS-ER & Russell et al. (1995, 2000) \\
CNRM & Centre National de Recherches Météoroliques, France & CNRM-CM3 & Salas-Mélia et al. (2005) \\
IPSL & Institute Pierre Simon Laplace, France & IPSL-CM4 & Marti et al. (2006) \\
MIROC & Centre for Climate Systems Research, Japan & MIROC3.2 & K-1 model developers (2004) \\
MPI & Max Planck Institute for Meteorology, Germany & ECHAM5/MPI-OM & Jungclaus et al. (2006) \\
MRI & Meteorological Research Institute, Japan & MRI-CGCM2.3.2 & Yukimoto et al. (2001) \\
CCM & Canadian Centre for Climate Modelling and Analysis, Canada & CGCM3.1 & Flato (2005) \\
\hline
\end{tabular}

distribution of rainfall, pan evaporation, land use, catchment attributes and other hydrologic parameters (Bari and Smettem, 2006). The three main components of a building block are (Bari and Smettem, 2003): (i) a two-layer unsaturated soil module (dry, wet and subsurface stores), (ii) a saturated subsurface groundwater module and (iii) a transient stream zone module. The upper-zone unsaturated store is represented by the variable infiltration capacity (VIC) model with a simple probability distribution function of the soil moisture capacity (Wood et al., 1992). The transient stream zone delineates groundwater-induced saturated areas along the stream zone while unsaturated zone represents water movement in the fluxes between the top layer dry and wet stores. Groundwater storage governs the groundwater and salt fluxes towards the stream zone. The runoff from RUs is routed using the Muskingum-Cunge routing scheme which subsequently flows through a channel network following the principles of open-channel hydraulics (Miller and Cunge, 1975). The model runs in a daily time step and runoff can be simulated at any nominated node (Bari et al., 2009). The LUCICAT model is used widely for water resources assessment in most of the Western Australian catchments and a few eastern states' catchments.

\subsection{Data, downscaling and modelling}

The hydrological impact of climate change on MurrayHotham catchment is assessed through projection of rainfallrunoff for the two IPCC emission scenarios A2 and B1 for the periods 2046-2065 and 2081-2100 respectively. The LUCICAT hydrologic model is applied to simulate future rainfallrunoff using downscaled and bias-corrected rainfall data of GCMs. A conceptual diagram of the hydrologic modelling using the LUCICAT model is shown in Fig. 2. At first input files with attribute of catchment, channels, nodes and rainfall stations were prepared through processing of a digital elevation model (DEM) of the catchment using ArcGIS. The attribute files were developed by dividing the catchment into 135 RUs. Land use history and pan evaporation data were considered as input for model calibration. The model was calibrated at five gauging stations (Fig. 1) for 1960-2004 and validated for 2005-2009 with recently developed $5 \mathrm{~km}$ grid rainfall produced by the Bureau of Meteorology, Australia (Jones et al., 2009). Next, downscaled GCM rainfall data were processed for hindcast (1961-2000) and different climate scenarios (A2 and B1) for 2046-2065 and 20812100. Downscaling of GCM data to a $5 \mathrm{~km}$ resolution (compatible to hydrologic modelling) was carried out by the $\mathrm{Bu}$ reau of Meteorology Statistical Downscaling Model (BoMSDM) which works with an analogue approach (Timbal et 


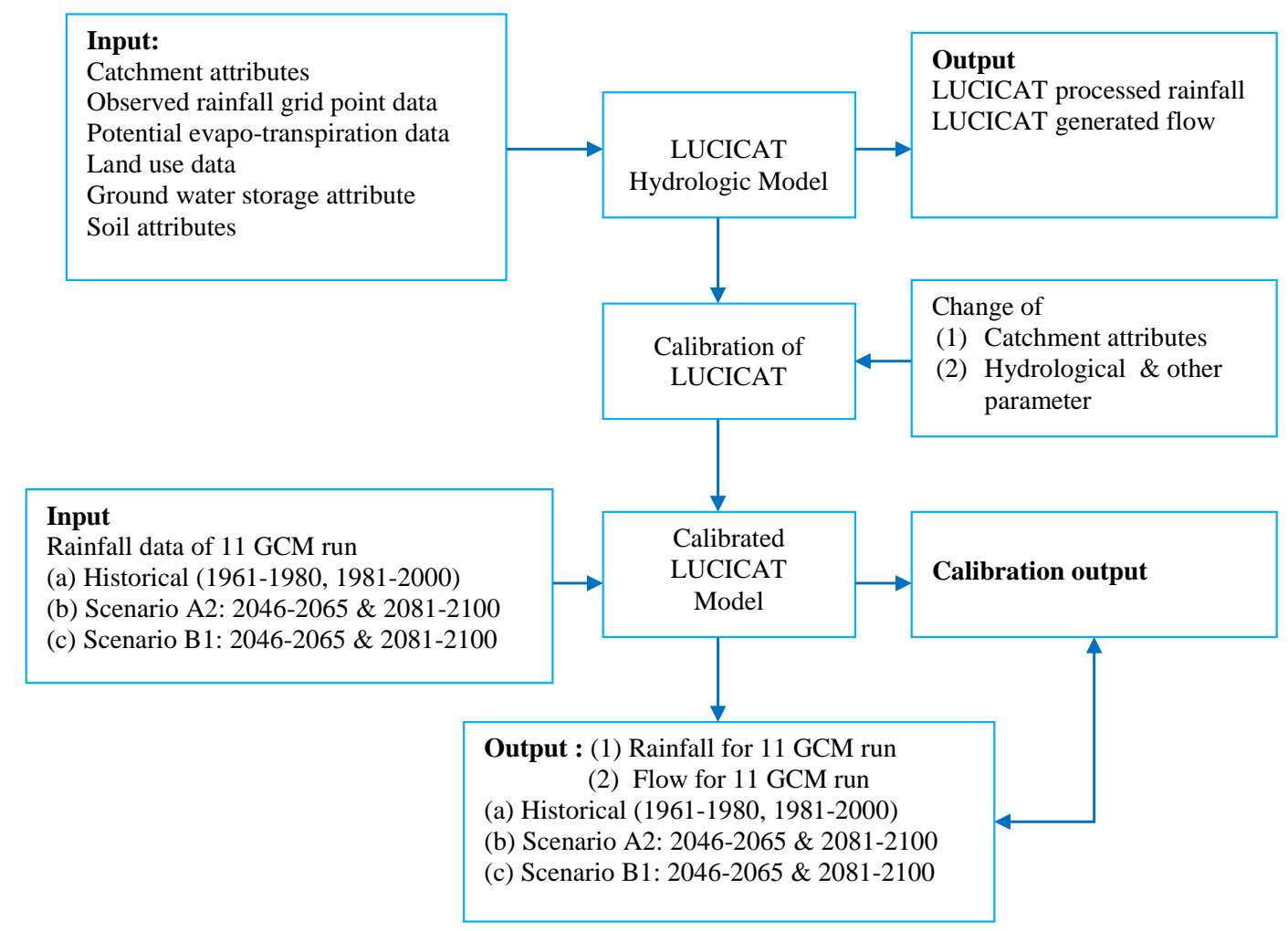

Figure 2. Conceptual diagram of the LUCICAT modelling process with climate change scenarios (modified from Islam et al., 2011).

al., 2009). The downscaled rainfall data were subsequently used as input into the calibrated model for generating rainfall and runoff scenarios. The annual rainfall processed for the hindcast period using downscaled GCMs data was compared with observed annual rainfall. A scale factor was developed for each of the GCMs to match the hindcast annual rainfall with the observed annual rainfall. The corresponding scaling factors are applied to downscaled daily rainfall data (20462065, 2081-2100) for the emission scenarios of A2 and B1. Processed rainfall and runoff scenarios along with historical data were then analysed, compared and presented. To address uncertainties involved with the GCM data, a multi-model ensemble approach (with 11 GCMs' data) was adopted and the ensemble mean was derived.

\subsection{Calibration}

The LUCICAT model has 29 model parameters which are grouped as (i) an estimated a priori group which do not need calibration and (ii) a variable set of eight physically meaningful parameters, which need calibration. Values of parameters in the priori set are determined from independent field investigation, published reports or previous modelling experience. The priori parameters represent empirical relationships of measurable characteristics of a catchment though observation, for example vegetation and soil properties, geomorphology and other topographic features. On the other hand, pa- rameters of the variable set can be estimated for a catchment from previous applications but these have to be calibrated with the objective of the best model fit. Hence, a combination of the two approaches is used to calibrate the model. As a fundamental building block, each RU of the model shares a set of model parameters. The model is calibrated for a catchment at each gauging station by a trial and error process against a standard set of criteria. The calibration criteria are (i) joint plot of observed and simulated daily flow series, (ii) scatter plot of monthly and annual flow, (iii) flow period error index (EI), (iv) Nash-Sutcliffe efficiency $\left(E^{2}\right)$, (v) explained variance, (vi) correlation coefficient (cc), (vii) overall water balance $(E)$ and (viii) flow duration curves. The EI is a numerical measure of the difference between the daily non-zero flow periods of observed and modelled flow. Overall water balance $(E)$ is the measure of difference of mean daily observed flow and mean daily modelled flow compared to mean daily observed flow for the period. The literature suggests that simulated mean annual flow at all gauging stations must be within $\pm 5-10 \%$ of the observed flow. At all the gauging stations in a catchment values of Nash-Sutcliffe efficiency and correlation coefficient for daily stream flow should be greater than 0.5 and 0.75 respectively while simulated daily flow duration curve should closely match the observed one (Bari et al., 2009). 


\section{Results and discussion}

In this section analysis of the observed (1961-2000) and projected (2046-2065 and 2081-2100) rainfall and runoff are presented for scenarios $\mathrm{A} 2$ and $\mathrm{B} 1$ at four gauging stations in the catchment. The time periods considered are: 19612000 (as historical), 1961-1980 (as past), 1981-2000 (as recent), 2046-2065 (as mid-century) and 2081-2100 (as late century).

\subsection{Catchment hydrology}

The runoff rate (runoff divided by rainfall) across the catchment has changed significantly in the last several decades. Figure 3 shows variation of annual flow with annual rainfall at the four gauging stations of the catchment for five different periods, 1961-1970, 1971-1980, 1981-1990, 1991-2000 and 2001-2009. The runoff rate was found to be higher in the period 1961-1970 followed by a relatively drier decade across the catchment. Then, compared to 1970 s, for last three decades runoff rate increased marginally in the upper part (low-rainfall area) of the catchment (Fig. 3b and c) at Marradong Road Bridge and Saddleback Road Bridge. On the other hand, runoff rate decreased downstream (the higherrainfall part) (Fig. 3d) at Yarragil. During the last three decades, overall, total runoff declined due to the absence of high rainfall in last three decades and this was found to be dominant in the high-rainfall part of the catchment. Similar changes of total runoff were also observed in other studies (CSIRO, 2009; DoW, 2010).

\subsection{Calibration and validation}

The model was calibrated at five gauging stations over the catchment for 1960-2004 and validated for 2005-2009 until the mean differences of observed and simulated annual average flow were found to be within $\pm 5.5 \%$. However, the result of Pumphreys Bridge gauging station is not presented here due to insufficient data. Results revealed that the model is adequate to describe annual flow, daily flow and flow duration. A systematic decline of annual rainfall was observed in SWWA since 1970 (IOCI, 2002; CSIRO, 2009) which resulted in subsequent decline of annual stream flow (Bari and Ruprecht, 2003). The overall (1960-2009) water balance $(E)$ varied from -0.01 to 0.08 (Table 3 ) across the catchment which means that variation of mean daily modelled flow with mean daily observed flow is -1 to $8 \%$ for the calibration and validation period (1960-2009). The overall (1960-2009) Nash-Sutcliffe efficiency $\left(E^{2}\right)$ varied from 0.47 to 0.84 and flow period error index (EI) varied from 0.86 to 1.05 across the catchment (Table 3). The correlation coefficient (CC) between daily observed and model flow has been used for both calibration and validation (Table 3). Figure 4 shows that the model can predict the trend of climate change in annual flows at four gauging stations. The $R^{2}$ value of model fitting for

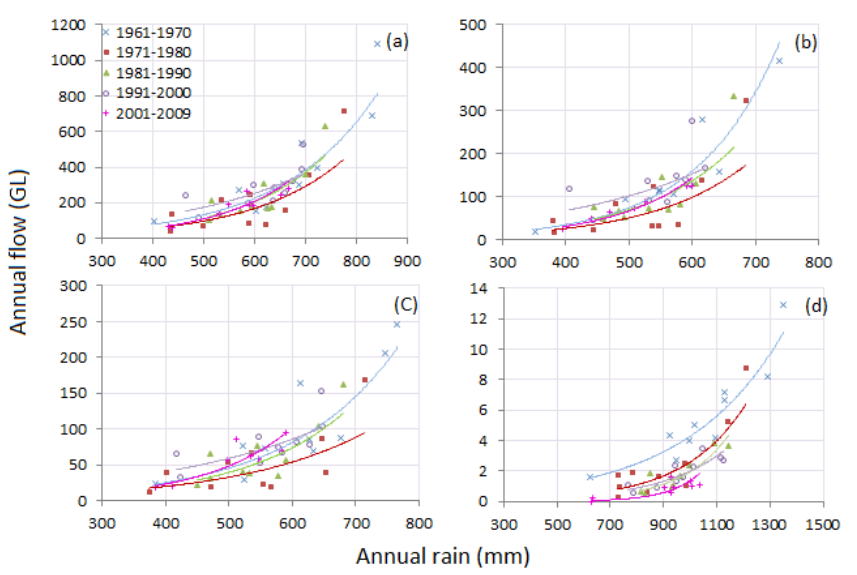

Figure 3. Changes in rainfall-runoff relationships in the catchment: (a) Baden Powell, (b) Marradong Road Bridge, (c) Saddleback Road Bridge and (d) Yarragill Formation.
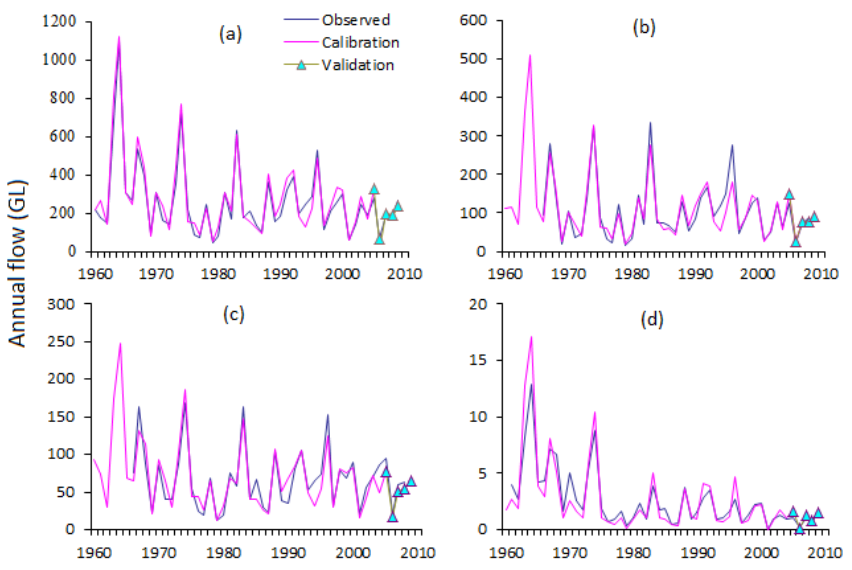

Figure 4. Observed annual in flow and modelled inflow at four gauging stations: (a) Baden Powell, (b) Marradong Road Bridge, (c) Saddleback Road Bridge and (d) Yarragil Formation.

observed and simulated flow was found within 0.83-0.94. The model was validated with observed data of 2005-2009 $(\mathrm{sd}= \pm 10 \%)$. Results revealed that the model can predict future annual flow successfully based on catchment rainfall.

In addition to annual flow, the model was also calibrated for daily flow (Fig. 5). The model was found to be well fitted for depicting daily flow (e.g. high, medium and low flow). Results also revealed that the model is capable of describing peaks, duration of flow and recession for all flow (e.g. high, medium and low flow) conditions. The daily flow model was validated with hydrographs at all gauging stations and it was found that it can predict future daily stream flow for the catchment and was very effective in describing peaks, duration of flow and recession (Fig. 5e, f). Table 3 presents a summary of model performance based on observed and simulated daily flow. 
Table 3. Goodness of fit for daily stream flow simulations.

\begin{tabular}{llrrrr}
\hline $\begin{array}{l}\text { Gauging } \\
\text { station }\end{array}$ & $\begin{array}{l}\text { Measure } \\
\text { of fit }\end{array}$ & $\begin{array}{r}\text { Nash-Sutcliffe } \\
\text { efficiency }\left(E^{2}\right)\end{array}$ & $\begin{array}{r}\text { Correlation } \\
\text { coefficient }(C C)\end{array}$ & $\begin{array}{r}\text { Overall water } \\
\text { balance }(E)\end{array}$ & $\begin{array}{r}\text { Flow-period } \\
\text { error index (EI) }\end{array}$ \\
\hline Baden Powell Water Spout & Overall & 0.70 & 0.84 & 0.07 & 1.00 \\
& Calibration & 0.70 & 0.84 & 0.07 & 1.01 \\
& Validation & 0.80 & 0.91 & -0.03 & 0.98 \\
\hline Marradong Road Bridge & Overall & 0.48 & 0.80 & -0.03 & 0.99 \\
& Calibration & 0.47 & 0.79 & -0.03 & 0.99 \\
& Validation & 0.81 & 0.94 & -0.03 & 0.99 \\
\hline Saddleback Road Bridge & Overall & 0.49 & 0.76 & -0.04 & 1.02 \\
& Calibration & 0.48 & 0.75 & -0.03 & 1.02 \\
& Validation & 0.84 & 0.92 & -0.12 & 1.00 \\
\hline Yarragil Formation & Overall & 0.56 & 0.75 & -0.01 & 0.86 \\
& Calibration & 0.56 & 0.75 & -0.01 & 0.90 \\
& Validation & 0.68 & 0.80 & 0.08 & 1.05 \\
\hline
\end{tabular}
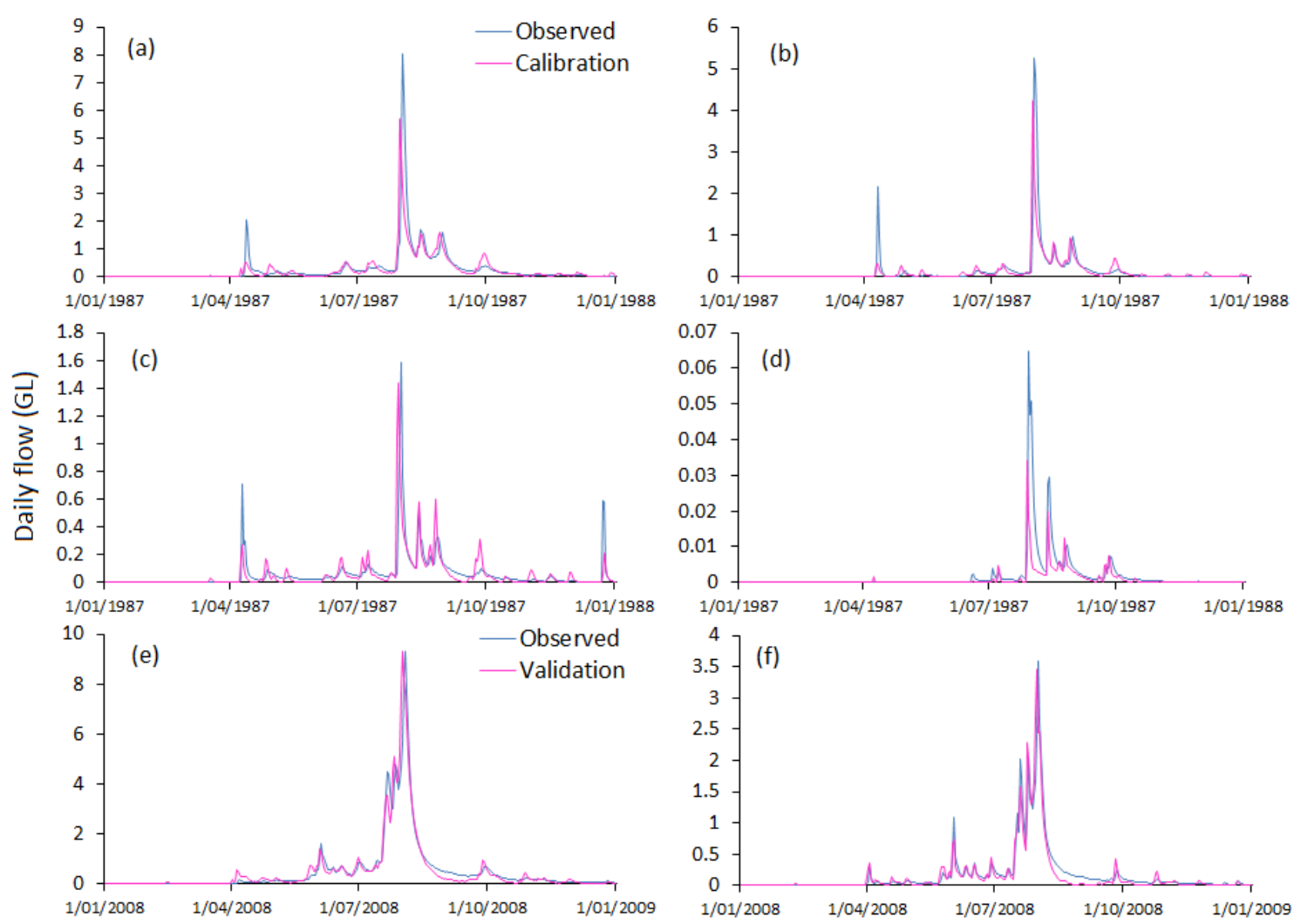

Figure 5. Example observed and modelled daily flow at four gauging stations at (a) Baden Powell, (b) Marradong Road Bridge, (c) Saddleback Road Bridge and (d) Yarragil Formation within the calibration period; (e) and (f) represent the same for the validation period at Baden Powell and Saddleback respectively.

\subsection{Variability of rainfall}

\subsubsection{Historical and projected annual rainfall}

Observed annual rainfall for the historical period (19602000) and projected annual rainfall for the mid (2046-2065) and late (2081-2100) century at four gauging stations of the catchment are presented in Fig 6. A summary of observed rainfall in the contributing catchments at the four gauging stations for the observed period and rainfall changes during the observed and projected periods compared to the observed 

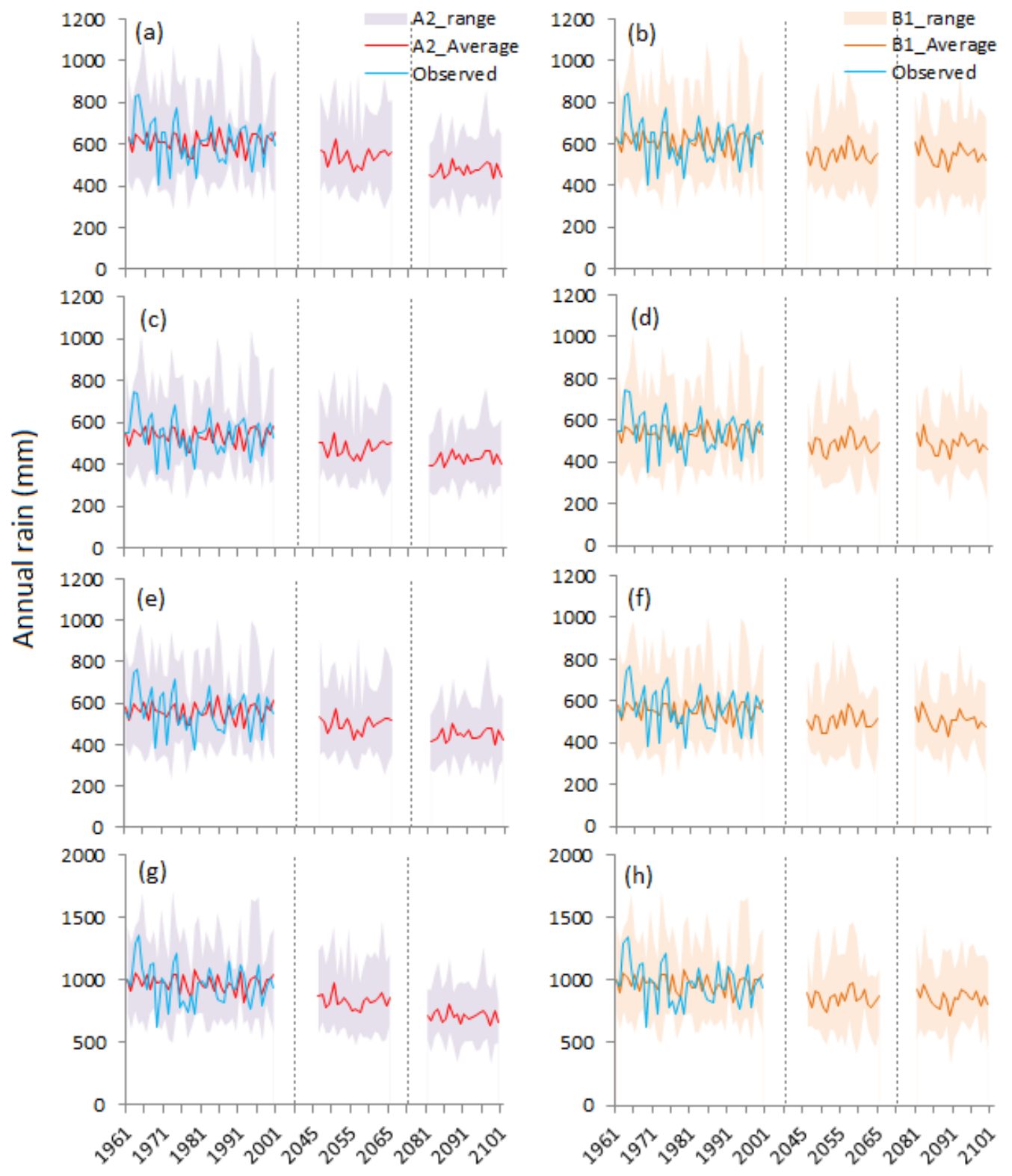

Figure 6. Observed and projected annual rainfall under scenarios A2 and B1 for the four gauging stations: (a) and (b) at Baden Powell, (c) and (d) at Marradong Road Bridge, (e) and (f) at Saddleback Road Bridge, (g) and (h) at Yarragil Formation. The average for projected rainfall is the ensemble mean of 11 GCMs and A2 and B1_range represent the maximum and minimum of all the GCMs.

past is presented in Table 4. In a catchment scale at Baden Powell, observed rainfall has shown a declined trend (Fig. 6) in recent times with mean annual rainfall decreasing by $2 \%$, from $623 \mathrm{~mm}$ to $609 \mathrm{~mm}$ (Table 4). Most of the rainfall reduction is due to the absence of a high rainfall event. For example, in recent times the 90th percentile rainfall has decreased by $11 \%$, 50th percentile rainfall has changed very little and 10th percentile rainfall has increased by $16 \%$. Details of rainfall variability for contributing catchment at four gauging stations for observed and projected periods are presented in Table 4. At Marradong Road Bridge, the contributing catchment is the lowest rainfall area in terms of mean annual rainfall with an historical mean annual rainfall of $547 \mathrm{~mm}$ and rainfall reduction during recent times is $2 \%$, while mean annual rainfall decreased from 552 to $542 \mathrm{~mm}$. The contributing catchment at Saddleback Road Bridge, also another lowrainfall part of the catchment, experienced the highest rainfall reduction $(3 \%)$ in terms of percentage reduction of mean annual rainfall in recent times. During recent times, the rainfall in the contributing catchment at Yarragil Formation experienced a reduction of mean annual rainfall of around $2 \%$ (Table 4). The contributing catchment at Yarragil belongs to 
Table 4. Observed and projected rainfall scenarios.

\begin{tabular}{|c|c|c|c|c|c|c|c|c|c|}
\hline \multirow[t]{3}{*}{$\begin{array}{l}\text { Gauging } \\
\text { stations }\end{array}$} & \multirow[t]{3}{*}{ Percentile } & \multicolumn{3}{|c|}{ Observed rainfall (mm) } & \multirow{3}{*}{$\begin{array}{r}\text { Change } \\
(\%)\end{array}$} & \multicolumn{4}{|c|}{$\begin{array}{c}\text { Change in average rainfall with } \\
\text { respect to the past }(\%)^{*}\end{array}$} \\
\hline & & \multirow{2}{*}{$\begin{array}{r}\text { Historical } \\
(1961- \\
2000)\end{array}$} & \multirow{2}{*}{$\begin{array}{r}\text { Past } \\
(1961- \\
1980)\end{array}$} & \multirow{2}{*}{$\begin{array}{c}\text { Recent } \\
(1981- \\
2000)\end{array}$} & & \multicolumn{2}{|c|}{ 2046-2065 } & \multicolumn{2}{|c|}{$2081-2100$} \\
\hline & & & & & & A2 & B1 & $\mathrm{A} 2$ & B1 \\
\hline \multirow[t]{4}{*}{ Baden Powell } & Q90 & 726 & 779 & 696 & -11 & -13 & -11 & -24 & -12 \\
\hline & Q50 & 622 & 622 & 623 & 0 & -15 & -16 & -24 & -12 \\
\hline & Q10 & 489 & 437 & 508 & 16 & -9 & -4 & -15 & 0 \\
\hline & Mean & 616 & 623 & 609 & -2 & -13 & -12 & -24 & -12 \\
\hline \multirow[t]{4}{*}{ Marradong Road Bridge } & Q90 & 646 & 690 & 607 & -12 & -15 & -10 & -29 & -11 \\
\hline & Q50 & 550 & 549 & 556 & 1 & -21 & -15 & -30 & -12 \\
\hline & Q10 & 439 & 381 & 445 & 17 & -17 & -5 & -22 & 0 \\
\hline & Mean & 547 & 552 & 542 & -2 & -13 & -12 & -23 & -12 \\
\hline \multirow[t]{4}{*}{ Saddleback Road Bridge } & Q90 & 677 & 717 & 645 & -10 & -13 & -10 & -22 & -12 \\
\hline & Q50 & 566 & 585 & 566 & -3 & -16 & -16 & -25 & -13 \\
\hline & Q10 & 423 & 398 & 451 & 13 & -8 & -4 & -12 & 0 \\
\hline & Mean & 564 & 573 & 555 & -3 & -13 & -12 & -22 & -11 \\
\hline \multirow[t]{4}{*}{ Yarragil Formation } & Q90 & 1140 & 1217 & 1114 & -8 & -15 & -13 & -27 & -15 \\
\hline & Q50 & 949 & 963 & 947 & -2 & -15 & -14 & -28 & -11 \\
\hline & Q10 & 765 & 729 & 815 & 12 & -15 & -10 & -25 & -8 \\
\hline & Mean & 964 & 975 & 953 & -2 & -15 & -12 & -27 & -12 \\
\hline
\end{tabular}

* Increase $(+)$, decrease $(-)$.

a high-rainfall part of the catchment with historical, past and recent mean annual rainfall of 964,975 and $953 \mathrm{~mm}$. As a result, the absolute amount of mean annual rainfall reduction $(22 \mathrm{~mm})$ is more than the higher-rainfall reduction experiencing part (18 $\mathrm{mm}$ at Saddleback Road Bridge) of the catchment (Table 4).

At Baden Powell during mid this century, including low rainfall, further reduction of rainfall is projected for both scenarios A2 and B1 (Fig. 6a and b). For instance, projections for scenarios $\mathrm{A} 2$ and $\mathrm{B} 1$ indicate 90th percentile rainfall reduction by 13 and $11 \%$, 50th percentile rainfall reduction by 15 and $16 \%$ and 10th percentile rainfall decrease by 9 and $4 \%$ (Table 4). Hence, during mid-century, all (high, medium and low) rainfall in the catchment is expected to decrease compared to that of the observed past under both scenarios. At Marradong Road Bridge, under scenario A2, the 50th and 10th percentiles of mean annual rainfall are projected to reduce by 21 and $17 \%$ respectively while the 90th percentile is projected to decrease by $15 \%$, resulting in an overall $13 \%$ reduction of rainfall during mid this century. Compared to observed rainfall in recent times, the projected high rainfall during mid-century is expected to remain close to the observed. Mean annual rainfall at Saddleback Road Bridge during midcentury is projected to decrease by 13 and $12 \%$ for scenarios $\mathrm{A} 2$ and $\mathrm{B} 1$, with most of the rainfall reduction due to a fall of high and medium rainfall. Compared to recent observed rainfall, projected high annual rainfall during mid-century is expected to remain similar to the observed, while medium and low rainfalls are projected to decrease. Downstream at
Yarragil Formation during mid-century mean annual rainfall is projected to fall by 15 and $12 \%$ under scenarios A2 and B1.

At Baden Powell, projected rainfall scenarios of the catchment for late this century varied significantly for scenarios A2 and B1 (Fig. 6a and b), with mean annual rainfall reduction of 24 and $12 \%$ respectively (Table 4 ). Across the catchment, rainfall projected under scenario B1 is similar to changes projected during mid this century while under scenario A2, further reduction of rainfall is projected. At Marradong during late century, projected mean annual rainfall reductions are 23 and $12 \%$ for scenarios A2 and B1. Mean annual rainfall reductions under scenarios B1 and A2 for Saddleback are 11 and $22 \%$ whereas for Yarragil the figures are 12 and $27 \%$.

\subsubsection{Spatial variation of rainfall}

The spatial distribution of mean annual rainfall over 20-year time periods and changes across the catchment are presented in Fig. 7. From the top end of the catchment, approximately two thirds of the catchment experienced below $700 \mathrm{~mm}$ mean annual rainfall during the past and recent times (Fig. 7a and b). Mean annual rainfall decreased during recent times, varying $3-30 \mathrm{~mm}$ across the catchment from east to west (Fig. 7k). In general, a low rainfall reduction happened in lower-rainfall areas while high rainfall reduction happened in high-rainfall areas, though the spatial distribution of rainfall change is different from the distribution of mean annual 

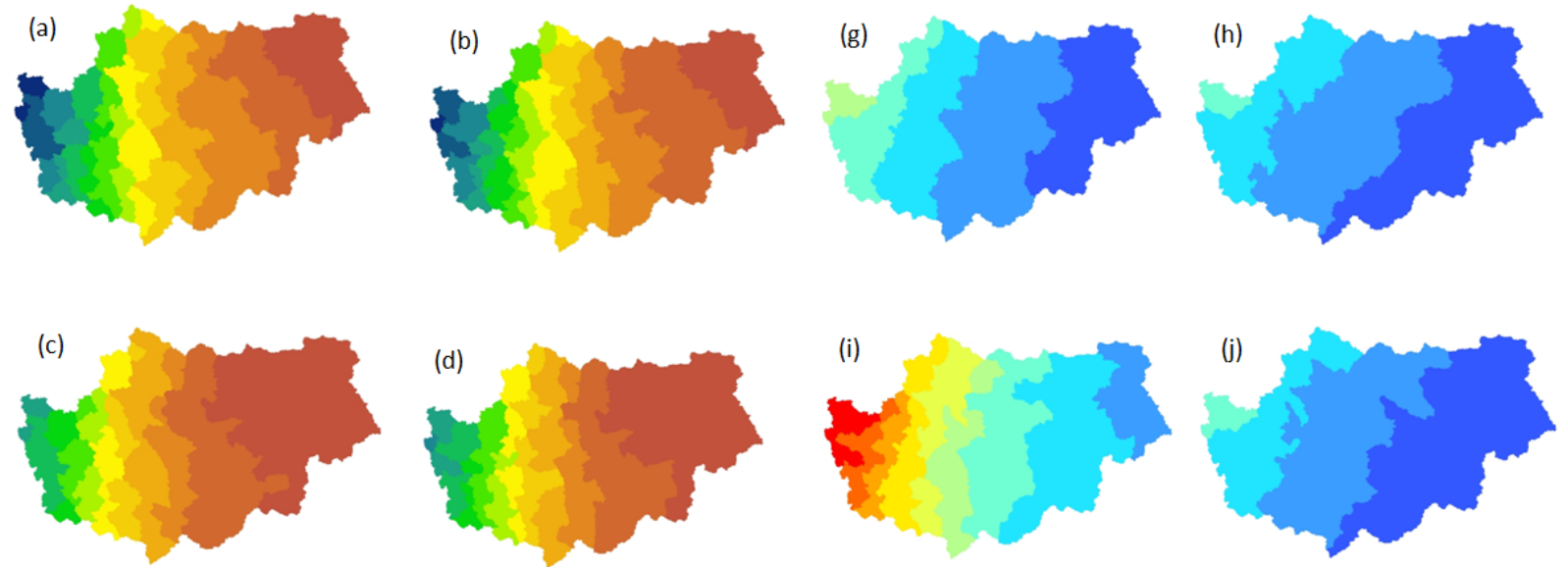

Rainfall change $\mathrm{mm} /$ year
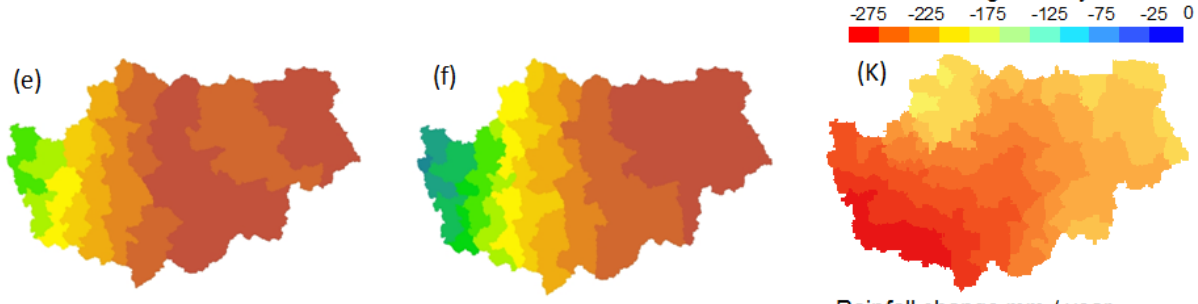

Rainfall change $\mathrm{mm} /$ year

$-30-26-23-20-17-14-11-8 \quad-5 \quad-2 \quad 0$

$400 \quad 500600700 \quad 800 \quad 900 \quad 1000$

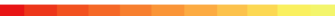

Figure 7. Spatial distribution of observed and projected (ensemble mean) rainfall and changes in average annual rainfall under scenarios A2 and B1. All mean annual rainfall presented in the figure is 20-year mean and changes are calculated considering 1961-1980 as base period. (a) and (b) are observed mean annual rainfall for the periods 1961-1980 and 1981-2000, (c) and (d) are for mid-century (2046-2065) while (e) and (f) are for late century (2081-2100) under scenarios A2 and B1 respectively. Changes in projected rainfall are presented as (g) and (h) for mid-century and (i) and (j) for late century under scenarios A2 and B1 respectively while observed change (1981-2000) in rainfall is presented as (k).

rainfall. The reduction of rainfall shows a gradual increase from the northeast corner towards the southwest end of the catchment in absolute terms (Fig. 7k).

The spatial distribution of projected mean annual rainfall for mid this century under scenarios A2 and B1 indicates further expansion of lower-rainfall areas from east to west, resulting in a contraction of high-rainfall areas (Fig. 7c and d). Also, very high rainfall areas (1000 $\mathrm{mm}$ and above) disappear from the catchment area. Figure $7 \mathrm{~g}$ and $\mathrm{h}$ show that a reduction of $0-150 \mathrm{~mm}$ of mean annual rainfall projected during mid this century compared to the past. The distribution of projected rainfall for late this century under scenario $\mathrm{B} 1$ is similar to that of during mid this century, but very different under scenario A2, indicating further reduction of rainfall across the catchment. During late this century under scenario A2, a reduction of $0-275 \mathrm{~mm}$ of mean annual rainfall is projected across the catchment (Fig. 7i). However, the distribution of reduction of projected rainfall varies from east to west as low to high, following the rainfall distribution pattern which is slightly different from the observed rainfall reduction distribution pattern.

\subsubsection{Temporal variation of rainfall}

The probability of exceedance of annual rainfall for observed (historical, past and recent) and projected periods for the scenarios at the four gauging stations across the catchment is presented in Fig. 8. The figure also presents variation of rainfall of different magnitude from the corresponding contributing catchment at the gauging stations over time. Here, high rainfall is referred to as the rainfall that has a percentage time of annual rainfall exceedance (PAE) of 0-25, while medium rainfall has a PAE of 26-75 and low rainfall has a PAE of 76-100 (Fig. 8). Across the catchment, high, medium and low rainfall varied differently in magnitude, following a pattern of change. For example, at the catchment scale at Baden Powell, high rainfall (PAE of 0-25) has decreased, low rainfall (PAE of 76-100) has increased, while medium rainfall (PAE of 26-75) has changed little in recent times. In general, greater reduction of rainfall is observed for higher rainfall with increasing magnitude of reduction from PAE of about 50 upwards. Across the catchment, low rainfall (PAE of 76100) varied differently compared to medium and high rainfall - in fact low rainfall increased variably across the catchment. 

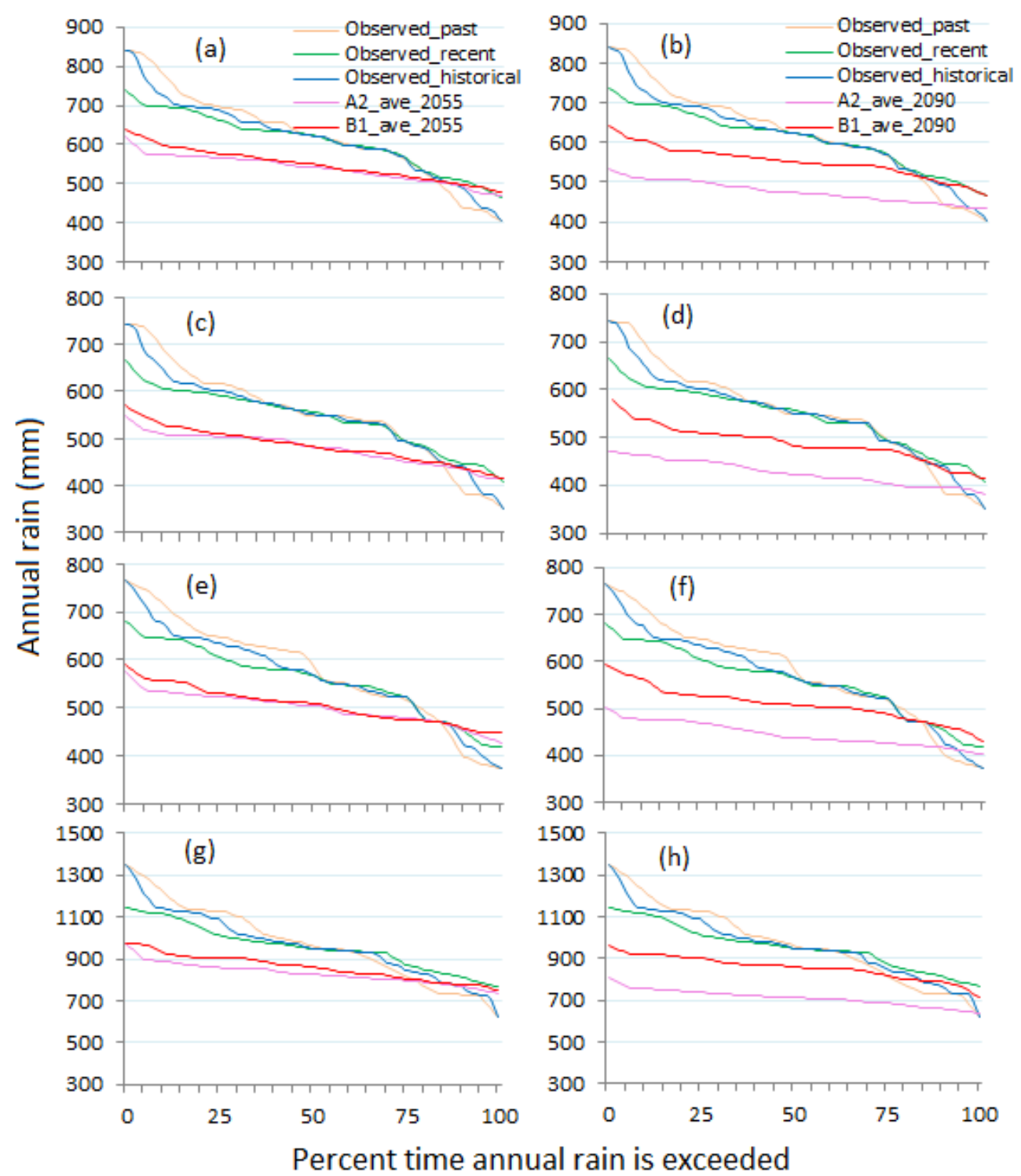

Figure 8. Probability of exceedance of observed and projected annual rainfall under scenarios A2 and B1 at four gauging stations: (a) and (b) at Baden Powell, (c) and (d) at Marradong Road Bridge, (e) and (f) at Saddleback Road Bridge, (g) and (h) at Yarragil Formation.

During mid-century, compared to the past, all annual rainfall including low annual rainfall is projected to decrease across the catchment for scenarios A2 and B1 with different magnitude (Fig. 8). The PAE of projected rainfall during mid-century at the gauging stations is very close for scenarios A2 and B1 except at Marradong Road Bridge. Higher reduction of all (high, medium and low) annual rainfall is projected under scenario A2 for the contributing catchment at Marradong compared to scenario B1. The gap (reduction magnitude) between recorded recent annual rainfall and projected annual rainfall widened from high to low rainfall varying across the catchment which is different from the observed pattern. It is understood that the projected pattern of PAE of changing rainfall may not necessarily follow the observed pattern of PAE but the projected pattern hints at some limitations of the data. An explanation of this limitation could be the presenting of GCM-derived rainfall data as an ensemble mean. It is argued that the ensemble mean in most cases does not reflect the individual pattern of each member of the ensemble. From Fig. 6 it is observed that each GCM has a tendency to generate an extreme high or low annual rainfall for some different years in a 20-year run period (e.g. 20462065). Thus, the ensemble mean annual rainfall of the 11 GCMs' data does not reflect the projected pattern of PAE, rather it is an average value of possible high and low annual rainfall. Also, observation of observed rainfall and hindcast rainfall (1961-2000) from Fig. 6 reveals that each GCM has a tendency to generate extreme high or low annual rainfall 
which is beyond the range of maximum or minimum for that period. Therefore, the PAE presented in Fig. 8 of the projected annual rainfall has upward bias for high rainfall and downward bias for low rainfall. For this reason the gap between observed recent and projected PAE of annual rainfall for mid this century has been widened from low to high rainfall. As a result, apart from the ensemble mean of GCMderived rainfall, a better way of presenting the data is necessary for improved understanding of the GCM-derived rainfall. A bias correction method will enhance further the understanding. During late this century under scenario A2, projected rainfall reductions (high, medium and low) are higher compared to the rainfall under scenario B1. The pattern of PAE for projected annual rainfall for B1 scenario during late this century is similar to that of the mid this century. For scenario A2, a clear downward parallel shift (with lower magnitude) of annual rainfall of PAE line is marked in Fig. 8 compared to observed recent or projected annual rainfall under scenario B1 during late this century. This indicates a straight decline of mean annual rainfall across the catchment. The underlying meaning of this is that the probability of getting a similar amount of rainfall as observed in recent times is projected to decrease significantly during late this century under scenario A2.

\subsection{Variability of runoff}

\subsubsection{Historical and projected annual runoff}

Observed annual runoff for the historical period (1961-2000) and projected mean annual runoff for the mid (2046-2065) and late (2081-2100) century at four gauging stations of the catchment is presented in Fig. 9. A summary of observed runoff at the gauging stations for historical (1961-2000), observed past (1961-1980) and observed recent (1981-2000) periods is presented in Table 5. The table also shows the changes in mean annual runoff for the observed periods and projected periods (mid and late this century) for scenarios A2 and B1. Mean annual runoff from the catchment at Baden Powell for the historical period (1961-2000) is 285 GL (Table 5) and a declining trend of annual runoff was observed with reduction of high flow over time (Fig. 9a). The catchment experienced substantial runoff reduction in recent times with $14 \%$ reduction of mean annual runoff, from 307 to $264 \mathrm{GL}$. At Baden Powell at a catchment scale, the reductions of 90th and 50th percentile of annual runoff in recent times are 44 and $10 \%$, from 692 to $389 \mathrm{GL}$ and from 233 to $210 \mathrm{GL}$ respectively, while the 10th percentile of mean annual runoff increased by around $34 \%$, from 85 to 114 GL (Table 5). Overall, higher annual runoff reduction was observed in high rainfall areas of the catchment (downstream) near Yarragil, with medium and low annual flow varied across the catchment over time. At Marradong Road Bridge $11 \%$ reduction of runoff occurred during recent time (Table 5). The contributing catchment at Marradong has experienced the high- est increase of lower annual runoff in recent times, with the 10th percentile annual runoff almost doubled compared to the past (Table 5) while high annual runoff decreased, and 90th and 50th percentile runoff fell by 50 and $16 \%$. During recent times, around $10 \%$ reduction of mean annual runoff has been observed at Saddleback Road Bridge with low annual flow increased (10th percentile flow increased by $30 \%$ ) while high and medium annual flow decreased. Highest (around 54\%) annual runoff reduction was noticed at Yarragil Formation in recent times, with mean annual runoff fall from 4 to $2 \mathrm{GL}$ where all (including low) flow reduced though low flow reduction (around 1\%) is much less compared to high flow reduction (Table 5).

Projections of runoff indicate further reduction for mid this century in the catchment (Fig. 9a, b), with mean annual runoff fall by 36 and $31 \%$, 90th percentile of annual runoff fall by 40 and $35 \%$, and 50th percentile of annual runoff fall by 43 and $41 \%$ under scenarios A2 and B1 respectively (Table 5). At Baden Powell, contrary to observed changes, low runoff is also projected to decrease, with 10th percentile annual runoff decrease by 54 and $34 \%$ under scenarios A2 and B1 (Table 5). At Marradong Road Bridge during mid this century mean annual runoff is projected to reduce by 41 and $39 \%$ under scenarios A2 and B1 respectively, mostly from the reduction of medium annual runoff with a 50th percentile annual runoff fall by 52 and $53 \%$ (Table 5). At Saddleback Road Bridge annual flow is projected to decrease (Fig. 9e, f) with reduction of all high, medium and low annual flow under both scenarios A2 and B1 (Table 5). During mid this century, mean annual runoff from the contributing catchment at Yarragil Formation is projected to decrease significantly compared to the observed past for both scenarios, A2 and B1.

During late this century (2081-2100), all annual runoff is projected to fall significantly under scenario A2 - the mean by $74 \%$, the 90 th percentile by $77 \%$, the 50 th percentile by $79 \%$ and the 10 th percentile by $80 \%$ (Table 5). Under scenario $\mathrm{B} 1$, all annual runoff is projected to fall - the mean by $38 \%$, the 90 th percentile by $50 \%$, the 50 th percentile by $34 \%$ and the 10th percentile by $34 \%$ (Table 5). At Marradong Road Bridge during late this century further reductions of annual runoff are projected, with mean annual runoff reduction of 76 and $45 \%$ under scenarios $\mathrm{A} 2$ and $\mathrm{B} 1$, mostly from the reduction of high and medium annual runoff (Table 5). At Saddleback Road Bridge during late this century under scenario A2, greater reduction of all annual flow (high, medium and low) is projected, with mean annual flow reduction of around $69 \%$ compared to the past. Runoff is also projected to reduce substantially at Yarragil Formation, particularly under scenario A2 during late this century, with mean annual runoff decrease of $93 \%$ compared to the observed past. 
Table 5. Observed and projected runoff scenarios.

\begin{tabular}{|c|c|c|c|c|c|c|c|c|c|}
\hline \multirow[t]{3}{*}{$\begin{array}{l}\text { Gauging } \\
\text { stations }\end{array}$} & \multirow[t]{3}{*}{ Percentile } & \multicolumn{3}{|c|}{ Observed runoff (GL) } & \multirow{3}{*}{$\begin{array}{r}\text { Change } \\
(\%)\end{array}$} & \multicolumn{4}{|c|}{$\begin{array}{l}\text { Change in average runoff with } \\
\text { respect to the past }(\%)^{*}\end{array}$} \\
\hline & & \multirow{2}{*}{$\begin{array}{r}\text { Historical } \\
(1961- \\
2000)\end{array}$} & \multirow{2}{*}{$\begin{array}{r}\text { Past } \\
(1961- \\
1980)\end{array}$} & \multirow{2}{*}{$\begin{array}{r}\text { Recent } \\
(1981- \\
2000)\end{array}$} & & \multicolumn{2}{|c|}{ 2046-2065 } & \multicolumn{2}{|c|}{$2081-2100$} \\
\hline & & & & & & A2 & B1 & A2 & B1 \\
\hline \multirow[t]{4}{*}{ Baden Powell } & Q90 & 537 & 692 & 389 & -44 & -40 & -35 & -77 & -50 \\
\hline & Q50 & 220 & 233 & 210 & -10 & -43 & -41 & -79 & -34 \\
\hline & Q10 & 92 & 85 & 114 & 34 & -54 & -34 & -80 & -34 \\
\hline & Mean & 285 & 307 & 264 & -14 & -36 & -31 & -74 & -38 \\
\hline \multirow[t]{4}{*}{ Marradong Road Bridge } & Q90 & 280 & 334 & 167 & -50 & -44 & -44 & -79 & -59 \\
\hline & Q50 & 105 & 108 & 92 & -16 & -52 & -53 & -82 & -49 \\
\hline & Q10 & 34 & 23 & 49 & 109 & -39 & -21 & -72 & -12 \\
\hline & Mean & 129 & 136 & 121 & -11 & -41 & -39 & -76 & -45 \\
\hline \multirow[t]{4}{*}{ Saddleback Road Bridge } & Q90 & 163 & 173 & 105 & -39 & -39 & -35 & -72 & -47 \\
\hline & Q50 & 68 & 71 & 66 & -7 & -48 & -45 & -76 & -44 \\
\hline & Q10 & 24 & 23 & 30 & 30 & -55 & -39 & -72 & -27 \\
\hline & Mean & 76 & 80 & 72 & -10 & -36 & -33 & -69 & -36 \\
\hline \multirow[t]{4}{*}{ Yarragil Formation } & Q90 & 6.7 & 8.3 & 3.5 & -58 & -57 & -50 & -92 & -66 \\
\hline & Q50 & 1.9 & 3.4 & 1.6 & -52 & -81 & -77 & -98 & -76 \\
\hline & Q10 & 0.6 & 0.6 & 0.6 & -1 & -86 & -81 & -99 & -80 \\
\hline & Mean & 3.0 & 4.1 & 1.9 & -54 & -64 & -60 & -93 & -67 \\
\hline
\end{tabular}

* Increase (+), decrease (-).

\subsubsection{Spatial variation of runoff}

The spatial distribution of mean annual runoff over 20-year timescale for the observed and projected periods is presented in Fig. 10. The figure also shows absolute differences of mean annual runoff between observed past and recent times and for projected periods with respect to the past (19611980). In general, like rainfall, runoff varied across the catchment from east to west as low $(20 \mathrm{~mm})$ to high $(160 \mathrm{~mm})$. But unlike the rainfall distribution, runoff had internal variation in distribution across the catchment, influenced by the river network and vegetation. Observed runoff reduction $(0-$ $45 \mathrm{~mm}$ ) during recent times varied across the catchment from west to east following the observed runoff pattern (Fig. 10k). During mid-century, around $0-100 \mathrm{~mm}$ runoff reduction is projected across the catchment for scenarios $\mathrm{A} 2$ and $\mathrm{B} 1$, compared to the past (Fig. 10g and h). The projected runoff reduction pattern is similar to that of the observed reduction pattern. Varying across the catchment, $0-130 \mathrm{~mm}$ reduction of mean annual runoff is projected under scenario A2 during late this century (Fig. 10i). These results almost see a disappearance of high runoff areas at the lower end of the catchment (Fig. 10e). Reductions for scenario B1 during late century are similar to the reductions projected during midcentury (Fig. 10j).

\subsubsection{Temporal variation of runoff}

The probability of exceedance of annual runoff for observed and projected periods at each gauging stations is presented in Fig. 11 with different time slices which also shows the temporal variability of runoff over the time periods. At the catchment scale at Baden Powell (Fig. 11a, b), high annual flow decreased significantly during recent times compared to the past, from 1092 to $630 \mathrm{GL}$, while medium flow remained similar and low flow increased slightly. Change of flow over time (past to recent) across the catchment is not uniform rather, it varies across the catchment. In the low-rainfall part of the catchment at Marradong Road Bridge (Fig. 11c, d) and Saddleback Road Bridge (Fig. 11e, f), reduction of high flow in recent times is relatively small in proportion compared to the high-rainfall part of the catchment at Yarragil Formation, (Fig. 11g, h). High flow fell from 506 to $334 \mathrm{GL}$ at Marradong Road Bridge, from 247 to $163 \mathrm{GL}$ at Saddleback Road Bridge and from 13 to 4 GL at Yarragil. Also, in the low-rainfall part of the catchment, medium flow did not change much and low flow increased slightly in recent times compared to the past. On the other hand, in the high-rainfall part of the catchment, medium flow decreased significantly in recent times while low flow changed very little in recent times.

During mid this century (2046-2065) for both scenarios, the pattern of projected ensemble mean annual flow across 

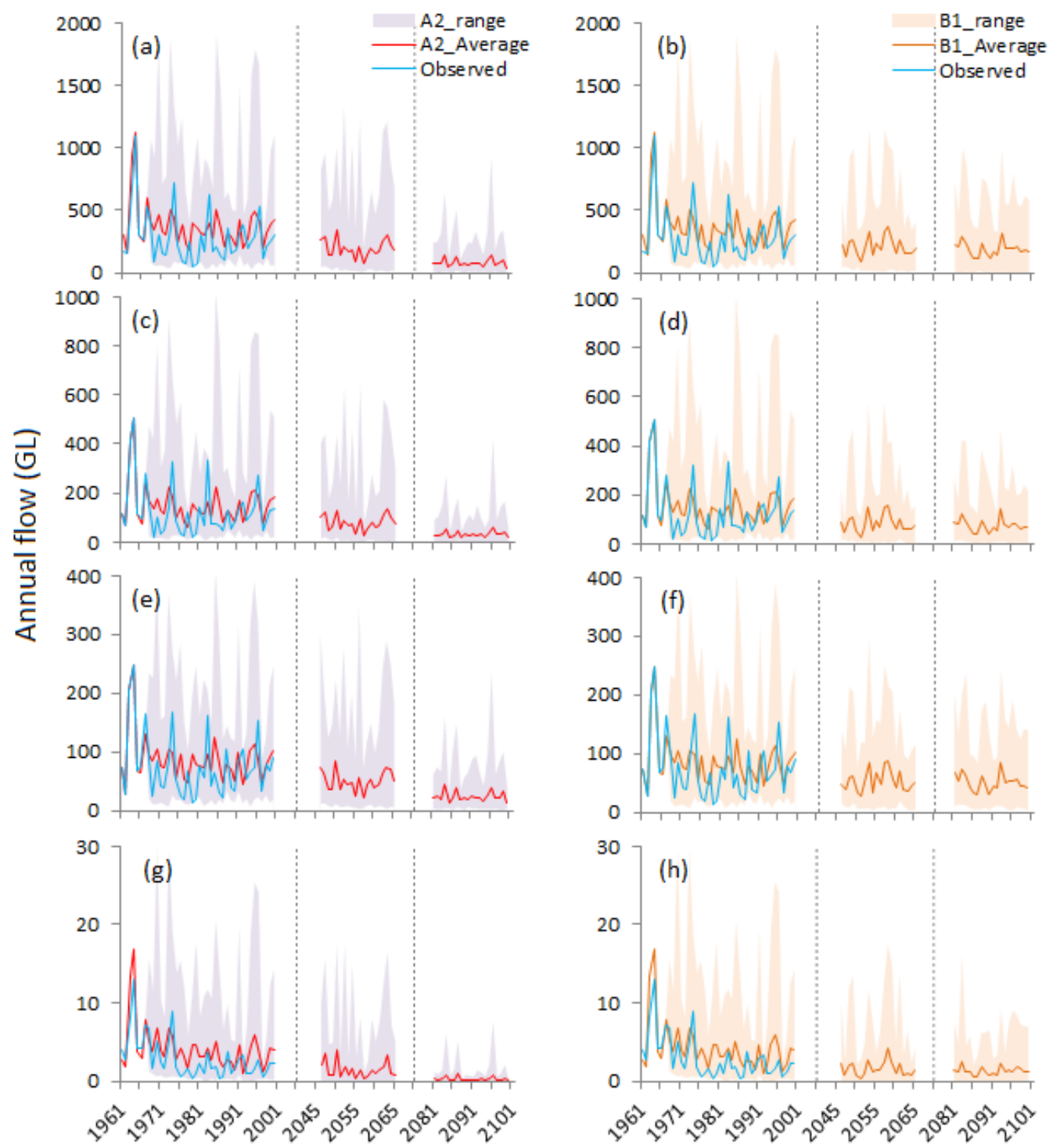

Figure 9. Projected changes in annual flow under scenarios A2 and B1: (a) and (b) at Baden Powell, (c) and (d) at Marradong Road Bridge, (e) and (f) at Saddleback Road Bridge, (g) and (h) at Yarragil Formation. The average for projected flow is the ensemble mean of 11 GCMs and $\mathrm{A} 2$ and B1_range represents the maximum and minimum of all the GCMs.

the catchment is similar. Across the catchment, except for Yarragil, the higher reduction of high annual flow is expected compare to that of recent times (Fig. 11a, c, e). At Yarragil, high annual flow is projected to remain similar to the observed recent (1981-2000) but projected to decrease compare to observed past (1961-1980) under both scenarios during mid this century (Fig. 11g). Medium and low flows are projected to decrease across the catchment under both scenarios during mid this century. During late this century (20812100) across the catchment, all annual flows (high, medium and low) are projected to fall significantly under scenario A2 (Fig. 11b, d, f, h). Higher reductions are projected in the highrainfall part of the catchment. Also under scenario B1, all annual flows are projected to fall across the catchment. In general, during late this century all projected annual flows (high, medium and low) under scenario A2 are significantly lower compared to annual flows under scenario B1.

Throughout the catchment at the gauging stations a reduction of rainfall has resulted in a 3-4 times higher reduction of runoff during mid and late this century. This can be explained through the water balance components of the LUCICAT model. The components of catchment water balance as captured in the model are rainfall, soil evaporation, transpiration, interception, storage change and stream flow. A summary of catchment water balance components for observed and projected periods is presented in Table 6. Transpiration and soil evaporation are the two largest components of water balance, followed by interception. Contributions of these 
Table 6. Catchment water balance components for the observed and projected period under scenarios A2 and B1.

\begin{tabular}{|c|c|c|c|c|c|c|c|}
\hline \multirow{3}{*}{$\begin{array}{l}\text { Water balance (WB) } \\
\text { Component }\end{array}$} & \multicolumn{3}{|c|}{ Observed annual mean } & \multicolumn{4}{|c|}{ Projected annual mean } \\
\hline & \multirow[t]{2}{*}{ 1961-1980 } & \multirow[t]{2}{*}{$1981-2000$} & \multirow[t]{2}{*}{ 2001-2009 } & \multicolumn{2}{|c|}{$2046-2065$} & \multicolumn{2}{|c|}{$2081-2100$} \\
\hline & & & & A2 & B1 & A2 & B1 \\
\hline Rainfall (mm) & 623 & 609 & 560 & 539 & 542 & 476 & 545 \\
\hline Interception (mm) & 77 & 71 & 67 & 69 & 70 & 66 & 70 \\
\hline Soil evaporation (mm) & 108 & 116 & 97 & 101 & 101 & 95 & 103 \\
\hline Transpiration (mm) & 373 & 367 & 348 & 338 & 338 & 311 & 337 \\
\hline Runoff (mm) & 56 & 45 & 33 & 34 & 35 & 16 & 32 \\
\hline Storage change (mm) & 9.6 & 10.0 & 15.5 & -3.6 & -1.7 & -11.6 & 2.0 \\
\hline \multicolumn{8}{|l|}{ WB components as } \\
\hline \multicolumn{8}{|l|}{ Percentage of rain } \\
\hline Interception $(\%)$ & 12.3 & 11.7 & 11.9 & 12.8 & 13.0 & 13.8 & 12.9 \\
\hline Soil evaporation (\%) & 17.3 & 19.0 & 17.2 & 18.8 & 18.6 & 20.0 & 18.9 \\
\hline Transpiration (\%) & 59.9 & 60.2 & 62.2 & 62.7 & 62.3 & 65.2 & 61.9 \\
\hline Runoff $(\%)$ & 9.0 & 7.4 & 5.8 & 6.3 & 6.4 & 3.4 & 5.9 \\
\hline Storage change $(\%)$ & 1.5 & 1.6 & 2.8 & -0.7 & -0.3 & -2.4 & 0.4 \\
\hline
\end{tabular}
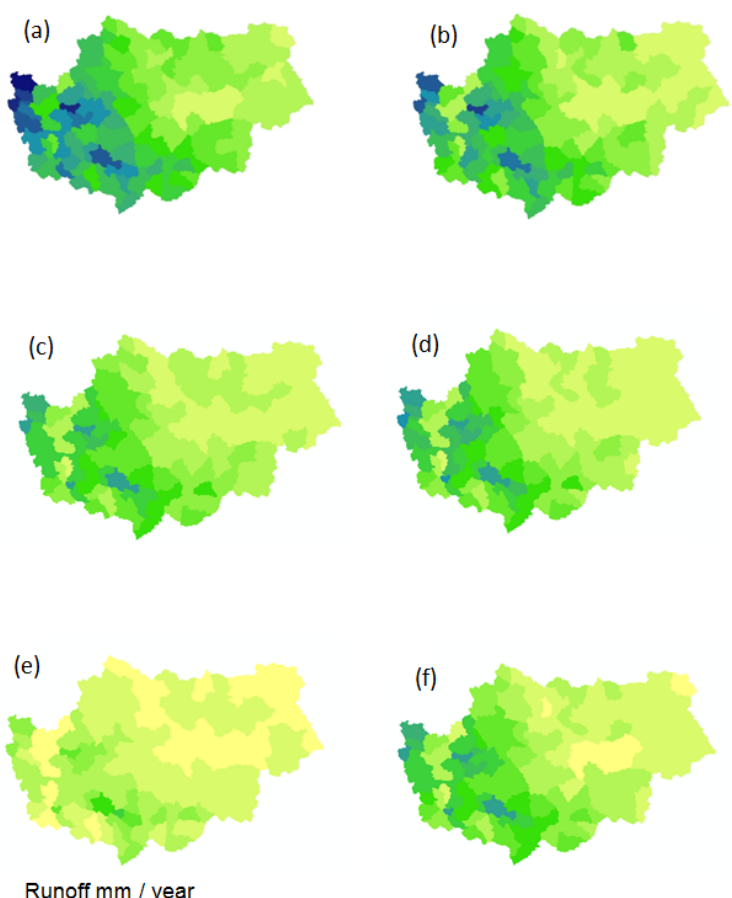

Runoff $\mathrm{mm} /$ year

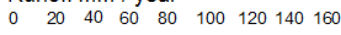
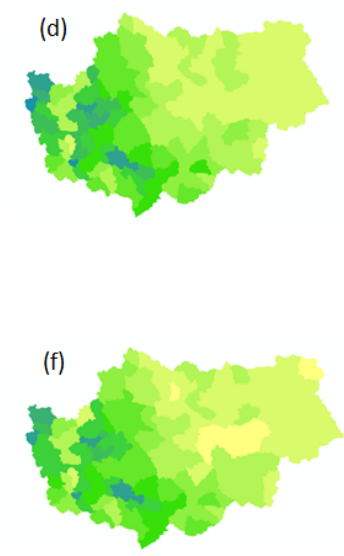
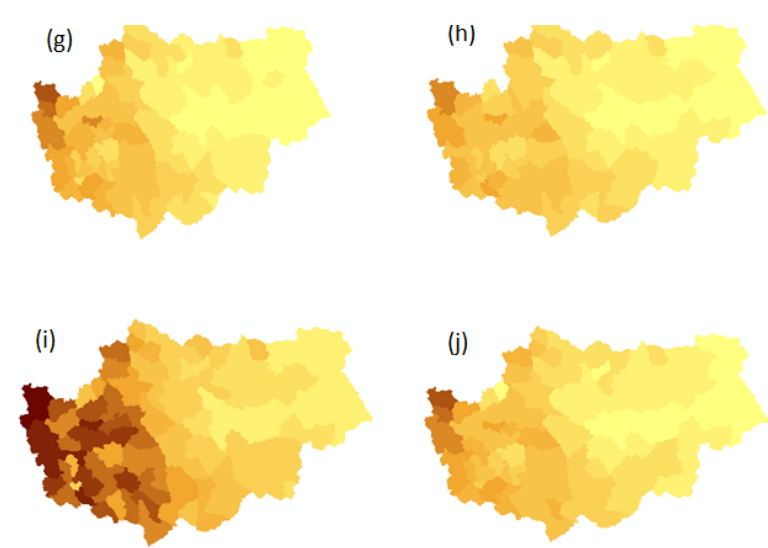

Runoff change $\mathrm{mm} /$ year $\begin{array}{llllllll}-130 & -110 & -90 & -70 & -50 & -30 & -10 & 0\end{array}$

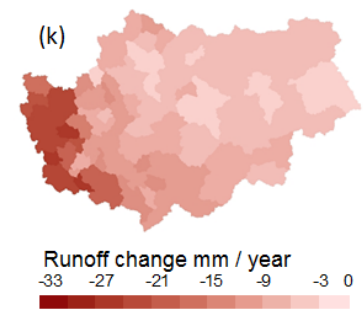

Figure 10. Spatial distribution of observed and projected (ensemble mean) runoff and changes in average annual runoff under scenarios A2 and B1. The mean annual runoff presented in the figure is 20-year mean and changes are calculated considering 1961-1980 as base period. (a) and (b) are observed mean annual runoff for periods 1961-1980 and 1981-2000, (c) and (d) are for mid-century (2046-2065) while (e) and (f) are for late century (2081-2100) under scenarios A2 and B1 respectively. Changes in projected runoff are presented as (g) and (h) for mid-century and (i) and (j) for late century under scenarios A2 and B1 respectively. Compared to the past, observed changes in runoff during 1981-2000 are presented in (k).

three components in the water balance were $90 \%$ during the observed past (1961-1980) and 91\% during observed recent (1981-2000) and the last decade. During recent time, interception, soil evaporation and transpiration components were $91 \%$ of overall water balance and a decrease in rainfall amount caused a decrease in runoff (as well as interception and transpiration) keeping groundwater storage unchanged. During mid this century (2046-2065) for both scenarios, 


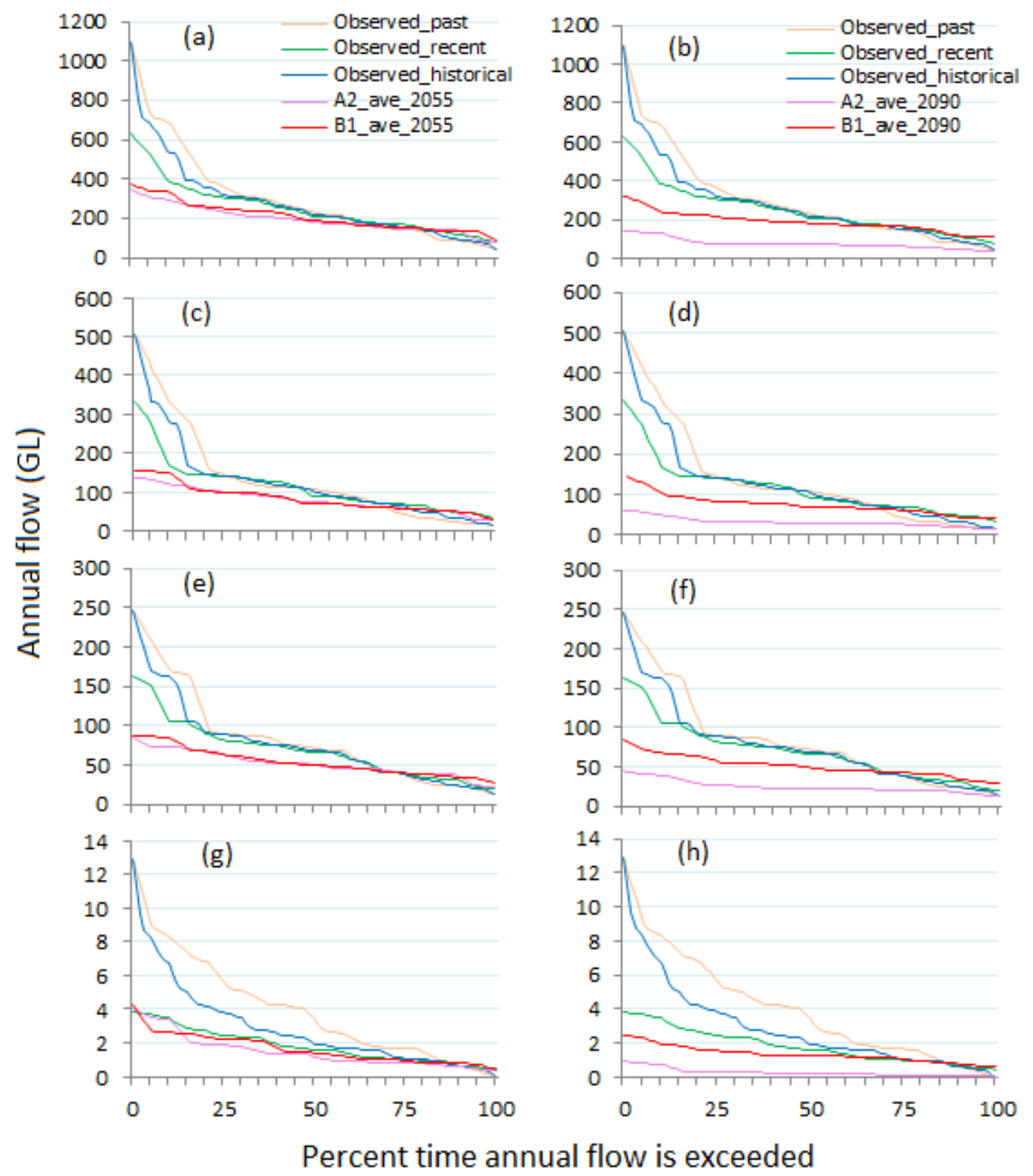

Figure 11. Flow duration curves as derived for observed and projected flow at four gauging stations: (a) and (b) at Baden Powell, (c) and (d) at Marradong Road Bridge, (e) and (f) at Saddleback Road Bridge, (g) and (h) at Yarragil Formation.

interception, soil evaporation and transpiration components contribute $94 \%$ of overall water balance and a decrease in rainfall mostly resulted in a decline in groundwater storage and runoff and a proportional decrease of other components of water balance as well. During late this century (2081-2100) under scenario A2, interception, soil evaporation and transpiration contribute $99 \%$ of overall water balance. Hence, further decrease in rainfall is projected to result in a significant decrease in runoff and more reductions in groundwater storage. Analysis of LUCICAT water balance components shows that interflow comprises the majority of stream flow (70-80\%) followed by surface runoff (around $20 \%$ ) and baseflow (3-20\%) in SWWA (Kitsios, 2009, Bari et al., 2005). LUCICAT water balance results of the previ- ous study (Kitsios, 2009, Bari et al., 2005) and the projected runoff changes found in this study confirm that each of the water balance components of stream flow would decrease in the future resulting in decreasing groundwater storage with interflow still the largest contributor of the future stream flow. A significant decline of interflow (from 43 to $72 \%$ ) and surface runoff is the main contributor to lower stream flow in the future. Reduction of baseflow (up to $43 \%$ ) would be linked to a decline in conceptual groundwater levels, changes in groundwater storage and soil moisture across the catchment under a future climate regime (Bari et al., 2005) which subsequently may lead to a reduction in baseflow, stream zone saturated areas and surface runoff. 
During the last 60 years or so, there have been major shifts in the structure of large-scale circulation of global atmosphere (Frederiksen and Frederiksen, 2007) and significant reductions in rainfall observed across SWWA (Smith, 2004; Nicholls, 2007; Bates et al., 2008; Frederiksen et al., 2011a, b; Risbey, 2011). Frederiksen et al. (2011c) related reduction in rainfall in SWWA since the mid-1970s, to changes in growth rate and structures of leading storm track and blocking modes. During winter, considerable reductions in growth rates of the leading storm track modes were observed across the southern part of Australia between 1949-1968 and 19751994 which continued into 1997-2007 (Frederiksen et al., 2011c). Frederiksen et al. noted that in recent times storm activity moved from latitudes of subtropical jet to latitudes of polar jet, and reductions in rainfall of SWWA since the mid-1970s are consistent with these changes in storm activity.

In addition, there might be some other factors causing lowering groundwater tables and runoff reduction in recent times in the Murray-Hotham catchment. Based on the findings from Figs. 7, 10 and 11, reasons of reduction runoff could be the reduction in rainfall quantity, intensity and absence of extreme weather events that could produce high rainfall and subsequent high runoff. The consequence of these three factors has a significant effect on catchment hydrology in the runoff generation process with further reduction of runoff in the catchment. For example, a lower number of all these three events contributes to lower water tables, consequently lower saturated areas which could produce saturation excess runoff. Thus, a lower water table results in a decrease of direct discharge to streams in the form of base flow. Also, interception and evaporation losses are higher for lower intensity events and in terms of proportion, evapotranspiration losses are higher for lower intensity rainfall events due to the demands of vegetation, resulting in less runoff. Silberstein et al. (2011) found that a drier hotter climate and legacy of historical (before 1975) forest management are major causes of stream flow decline since 1975 in catchments in the northern Jarrah Forest of SWWA. Their analysis of 18 catchments found that many streams that were once perennial are now ephemeral and now have longer periods without flow. Other causes of stream flow decline in recent times, particularly during the last decade, include the effect of drought years (e.g. 2001 and 2006), progressive loss in connection between groundwater and streams and reduced rate of groundwater recharge.

\subsection{Future projection for water resources planning}

Although water resources managers and policy makers are interested to know about climate change impact on rainfall and runoff in the longer term, they are more interested to know about impact in the shorter term (e.g. decadal). In this section, decadal changes of rainfall and runoff are presented particularly to meet the need for water resources managers and policy makers with the aim of developing a tool which would be useful for planning future water resources. The decadal mean of annual rainfall reduction and corresponding runoff reduction across the catchment at the four gauging stations is plotted (Fig. 12) for observed and projected periods under the scenarios, considering 1961-1970 as base period. Each point in Fig. 12 is a decadal change of runoff with respect to decadal change of rainfall at a particular gauging station. From the plot, for a particular change in future rainfall from a contributing catchment at a gauging station, the likely change of future runoff at the gauging station can be calculated in the decadal time period. For example, at Saddleback Road Bridge, $10 \%$ reduction of mean annual rainfall (compared to the past, 1961-1970) will result in around a $40 \%$ reduction of runoff. As the amount of mean annual rainfall and runoff for the past are of known quantity (Table 1), the corresponding quantity for any desired assumption can be calculated. Hence, Fig. 12 could be used as a tool for water resources planning.

In Fig. 12, a strong relationship is observed between rainfall reduction and corresponding runoff reduction, though the relationship is not uniform across the catchment over time. Highest runoff reduction is observed at Yarragil Formation and in terms of time period, highest reduction of rainfall is observed during the last decade. The second highest decadal rainfall reduction across the catchment was observed during 1971-1980 and after that, for the next two decades, rainfall reduction was relatively lower (Fig. 12). Hence, as rainfall and runoff reduction are not following a continuous trend of increasing or decreasing over time across the catchment, it is hard to make a projection for the future likely scenario of rainfall and runoff based on the observed data except with GCMs. Apart from for Yarragil, the decadal rainfall runoff reduction relationship is consistent across the catchment. At Yarragil, runoff reductions are relatively higher during the 1980s and 1990s. Across the catchment at the four gauging stations the average runoff reduction is 4.41 times the rainfall reduction. This supports the findings of other similar studies for catchments in Western Australia (Charles, et al., 2007; Kitsios et al, 2009; and Smith, et al., 2009) and in Australia as a whole (Chiew, 2006).

Under scenario B1, during mid and late this century, decadal mean annual rainfall is projected to decrease by from 12 to $20 \%$ and corresponding runoff is projected to decrease by from 40 to $80 \%$. As noted in Sect. 4.4, as for observed, higher runoff reduction is projected in the high-rainfall part of the catchment (at Yarragil Formation). For scenario A2, during mid this century, rainfall and runoff reduction projections are similar to that of B1 for the same period. But further higher rainfall and runoff reduction are projected for late this century for scenario A2 with the decadal mean annual rainfall reduction ranging from 25 to $35 \%$ and corresponding runoff reduction from 75 to $98 \%$ across the catchment. The ratio of projected decadal reduction of runoff to rainfall across the catchment under scenario A2 is 3.02 , slightly 


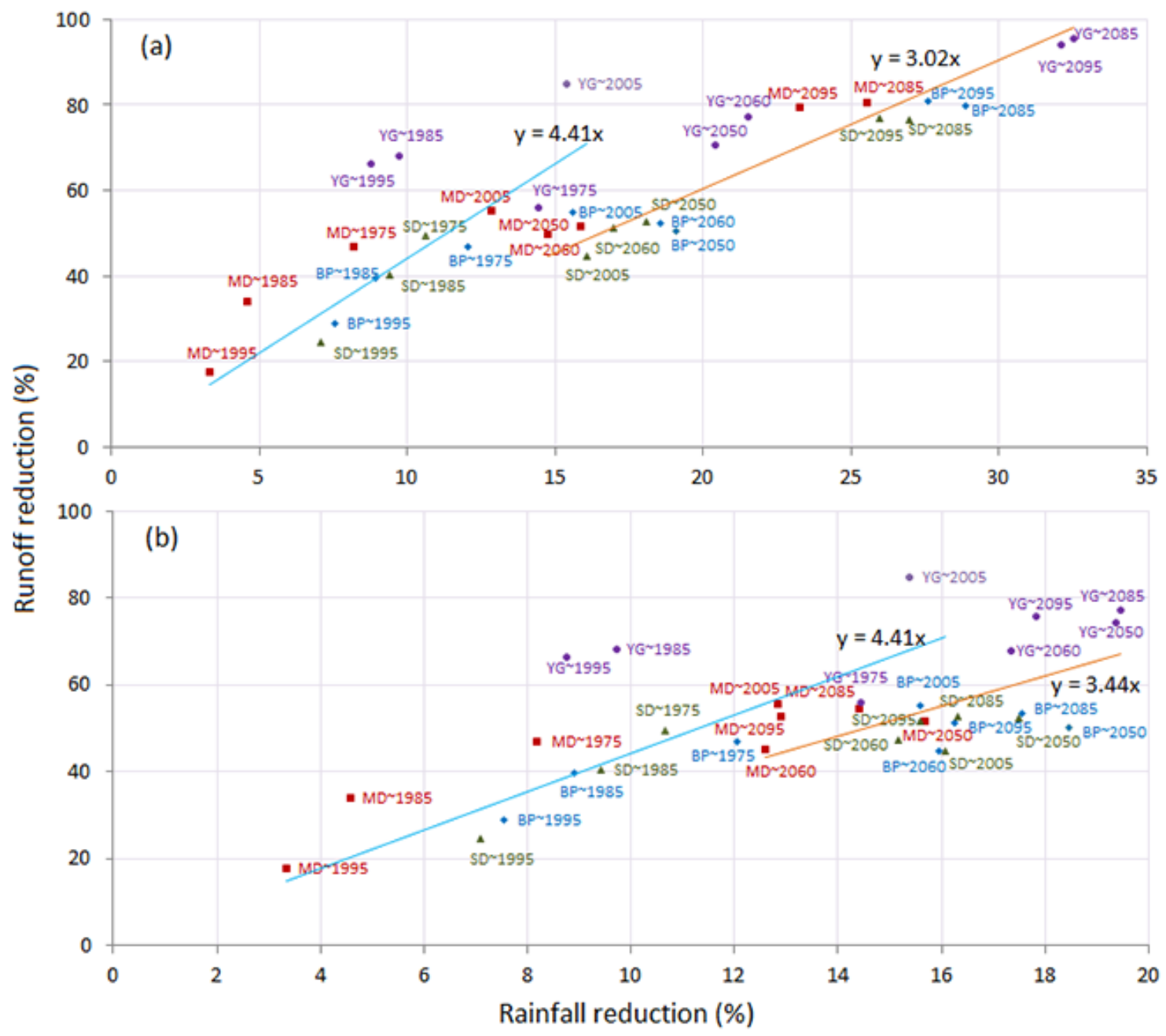

Figure 12. Observed and projected rainfall and flow change under different scenarios across the catchment at the four gauging stations Baden Powell (BP), Marradong Road Bridge (MD), Saddleback Road Bridge (SD) and Yarragil Formation (YG): (a) under scenario A2 and (b) under scenario B1. Each point in the plot represents the 10-year mean of runoff reduction associated with the corresponding rainfall reduction (observed for 1971-2009 and projected for 2046-2065 and 2081-2100) at a particular gauging station. For 2001-2009, the mean is for 9 years except for Marradong Road Bridge and Saddleback Road Bridge for which the mean is taken over 8 years. All reductions are computed considering 1961-1970 as base period.

less than the ratio under scenario B1 (3.44) (Fig. 12). But, under scenario A2, particularly during late this century, the percentage reduction of rainfall and runoff goes far beyond the already observed changes and also the projected changes for mid-century, resulting in a very dry catchment. Overall, runoff reduction compared to rainfall reduction is projected to decrease (3.02 and 3.44) during mid and late this century compared to the observed ratio (4.41) due to further drying out of the catchment.

\subsection{Uncertainty and its practical implication}

There are considerable uncertainties involved in different stages of the overall process of hydrological impact assessment of climate change on water resources at the catchment level, particularly using GCM data. Future rainfall and runoff scenarios developed here (Figs. 6 and 9) show that the range of rainfall and runoff varies widely. In climate change impact studies, GCMs are the largest source of uncertainty (Wilby and Harries, 2006; Nóbrega et al., 2011; Hughes et al., 2011). Also, choice of downscaling techniques can significantly affect the outcome of hydrological impact studies and are a large source of uncertainty (Coulibaly, 2008; Dibike and Coulibaly, 2005). In addition, selection of the hydrologic model, appropriate model parameterization, understanding the assumptions and limitations of the model and estimates of uncertainty associated with the modelling approach play significant role in climate change impact studies (Surfleet et al., 2012). Here, for simplicity of the study, evapotranspiration and vegetation cover in the catchment for 
future periods are assumed to remain similar to that of the historical period. Also, we have not considered the effect of increased level of $\mathrm{CO}_{2}$ emission, increase in temperature, changes in humidity and wind speed on the hydrologic process of the catchment under the scenarios (A2 and B1). Fu et al. (2007) found that stream flow response to rainfall changes is non-linear and also that a temperature change has a significant effect on stream flow changes in a catchment. In this study we did not consider the effect of temperature changes on runoff change under the climate scenarios. Hence, critical evaluation is required to use the results of hydrological impact study for water resources planning as the results involve considerable uncertainties. Therefore, instead of using a single model output, a multi-model ensemble approach is adopted in most of the recent impact studies to address the uncertainties. With the ensemble approach, rainfall and runoff series generated by a combination of GCMs provide a better picture of possible future change and variability of a rainfall and runoff regime, which is particularly useful for water resources managers (Coulibaly, 2008). However, Arnell (2011) argues that the ensemble mean is not an appropriate generalized indicator of hydrologic impact of climate change as the ensemble mean cannot reflect clustering of results in projected changes of runoff. To make better informed decisions, a reliable method to minimize uncertainty is necessary. Development of an approach to reduce uncertainty of GCM-derived rainfall and runoff at the catchment scale is currently in progress in association with this study.

\section{Conclusions}

The hydrologic impact of 21 st century climate change on rainfall-runoff of the Murray-Hotham catchment has been assessed by adopting a multi-model ensemble approach, using 11 downscaled and bias-corrected GCM data sets for emission scenarios A2 and B1, where each of the models is an ensemble member. Calibration results of the model indicate that the model is well calibrated at all the gauging stations and that the model is capable of depicting the climate change trend (from high runoff in the past to recent decline in runoff). The rainfall runoff plot shows that runoff rate across the catchment changed significantly during the last five decades, varying across the catchment. Overall, annual rainfall and runoff across the catchment decreased in recent times compared to the past period mostly due to the lack of high-rainfall event in recent times. Derived rainfall and runoff scenarios for mid and late this century draw a broader picture of possible change and variability of rainfall and runoff in the catchment as represented by the climate models and emission scenarios, A2 and B1. To address uncertainty (variation) among the GCMs and understand the change in rainfall and runoff, results have been presented as ensemble mean, 10th and 90th percentile, and range (of maximum and minimum).
The ensemble mean, including the range of annual rainfall and runoff across the catchment, is projected to decrease during mid and late century, under the emission scenarios. During mid this century, when the A2 and B1 emission scenarios are similar, the rainfall and runoff reductions are similar, but during late this century the reductions are greater for emission scenario A2 compared to B1. The spatial distribution of projected rainfall and runoff shows that higher rainfall and runoff reductions are projected to occur in the higher-rainfall part of the catchment, in the downstream areas, which are similar to that of the observed rainfall and runoff reduction pattern. Overall, all (high, medium and low) rainfall and runoff is projected to decrease during mid and late this century in the catchment compared to the past. The projected runoff reduction is higher compared to rainfall reduction under both scenarios, resulting in a drier catchment. Water balance components for observed and projected periods indicates that significant reductions in groundwater storage changes are projected to occur during mid and late this century, which means a significant lowering of groundwater level. Lower water level thus is a major cause of declining runoff in the future with a decline in rainfall. Other reasons for rainfall and subsequent runoff reductions in the catchments are changes in storm track, lack of high-rainfall event and changes in catchment hydrology (e.g. lower groundwater level, lower inter-flow etc.). Although the derived rainfall and runoff using GCM data have varied in a wide range in magnitude, most of the GCMs have shown some degree of agreement in climate signs, with a reduction of rainfall and runoff in the catchment for the future. Hence, considering the variability among the ensemble members, the results can be useful for water resources managers and policy makers in planning water resources.

Results of this study indicate that the recent declining trend of rainfall and runoff in SWWA is likely to continue during mid and late this century, resulting in lower flow to the dams and a subsequent lower availability of surface water. Hence, water resources managers and policy makers will have to rely more on groundwater, desalination or other sources of water (e.g. recycling) for Perth water supply. The plot of decadal change of rainfall and runoff for observed and projected periods at each gauging station is likely to be useful to the water resources managers and policy makers in planning future surface water resources in SWWA. Each point in the plot is a decadal change of runoff with respect to decadal change of rainfall at a particular gauging station. This plot presents how rainfall and runoff has changed in a contributing catchment during the observed period during a decade and how the rainfall and runoff would change as represented by the GCMs and climate scenarios (A2 and B1). From the hindcast data, it is observed that GCM-derived annual rainfall and runoff have a tendency for extreme high or low value (which is much higher or lower) beyond the observed range in a particular time period. Hence, considerable bias remains in the findings in this study. Also, when presenting annual 
rainfall and runoff data to look for the probability of annual exceedance, it is inferred that the ensemble mean has upward and downward bias for higher and lower values for rainfall and runoff respectively. Thus, variation among GCMs in sign and magnitude, when presenting data as ensemble mean (in probability of annual exceedance), are key limitations observed in this study. In addition, the downscaling technique, hydrologic model selection and model parameterization remain as usual sources of uncertainties as in most climate change impact studies. Therefore, considerable uncertainty is involved in the findings, and to make the findings more credible for use in real-life decision making, reduction of uncertainty is necessary. Post-processing bias correction of GCM-derived rainfall and runoff can be performed to reduce uncertainty, and development of a post-processing bias correction method is in progress along with this study. A detailed investigation of the elasticity of runoff changes can be carried out to understand the likely hydrologic changes of a catchment due to lower rainfall in the future. Performance of the GCMs could be evaluated by comparing observed rainfall and runoff with hindcast rainfall and runoff. This would help in selecting high-performing GCMs in this catchment and an ensemble of high-performing GCMs could attract better confidence than the ensemble of all GCMs in representing the hydrologic impact of climate change.

Acknowledgements. This study is part of a Ph.D. research project carried out by the first author. We acknowledge the data support of the Bureau of Meteorology, Australian Government and Department of Water, Government of Western Australia. We thank two reviewers for their constructive comments on an earlier version of the manuscript which helped in improving the manuscript.

Edited by: A. Ghadouani

\section{References}

Arnell, N. W.: Uncertainty in the relationship between climate forcing and hydrological response in UK catchments, Hydrol. Earth Syst. Sci., 15, 897-912, doi:10.5194/hess-15-897-2011, 2011.

Anwar, A. H. M. F. , Bari, M. A., Want, R. M., and Islam, S. A.: The effect of climate change on stream flow reduction in MurrayHotham river catchment, Western Australia, Sustainable Water Solutions for a Changing Urban Environment, Singapore, 4-8 July 2011, 2011.

Bari, M. A. and Ruprecht, J. K.: Water yield response to land use change in south-west Western Australia, Salinity and Land Use Impacts Series Report No. SLUI 31, Department of Environment, Perth, Western Australia, 2003.

Bari, M. A. and Smettem, K. R. J.: Development of a salt and water balance model for a large partially cleared catchment, Aust. J. Water Resour., 7, 83-99, 2003.

Bari, M. A. and Smettem, K. R. J.: A daily salt balance model for stream salinity generation processes following partial clearing from forest to pasture, Hydrol. Earth Syst. Sci., 10, 519-534, doi:10.5194/hess-10-519-2006, 2006.
Bari, M. A., Berti, M. L., Charles, S. P., Hauck, E. J., and Pearcey, M.: Modelling of streamflow reduction due to climate change in Western Australia - A case study, in: MODSIM 2005 International Congress on Modelling and Simulation, edited by: Zerger, A. and Argent, R. M., Modelling and Simulation Society of Australia and New Zealand, December 2005, 482-488, 2005.

Bari, M. A., Shakya, D. M., and Owens, M.: LUCICAT Live - A modelling framework for predicting catchment management options, 18th World IMACS Congress and MODSIM09 International Congress on Modelling and Simulation, Cairns, Australia, 13-17 July 2009, 3457-3463, 2009.

Bari, M. A., Amirthanathan, G. E., and Timbal, B.: Climate change and long term water availability in south-western Australia - an experimental projection, Practical Responses to Climate Change National Conference 2010, Hilton on the Park, Melbourne, Australia, 29 September-1 October 2010, 2010.

Bates, B., Hope, P., Ryan, B., Smith, I., and Charles, S.: Key findings from the indian ocean climate initiative and their impact on policy development in Australia, Climatic Change, 89, 339-354, doi:10.1007/s10584-007-9390-9, 2008.

Beeston, G. R., Hopkins, A. J. M., and Shepherd, D. P.: Landuse and vegetation in Western Australia, Resource Management Technical Report no 250, Department of Agriculture and Food, Perth, Western Australia, 2002.

Commonwealth Scientific and Industrial Research Organisation (CSIRO): Surface water yields in south-west Western Australia, a report to the Australian government from the CSIRO southwest Western Australia sustainable yields project, CSIRO water for a healthy country flagship, Commonwealth Scientific and Industrial Research Organisation, Australia, 171 pp., 2009.

Coulibaly, P.: Multi-model approach to hydrologic impact of climate change, From Headwaters to the Ocean, Hydrological Change and Water Management - Hydrochange 2008, Kyoto, Japan, 249-255, 2008.

Cherkauer, K. A. and Sinha, T.: Hydrologic impacts of projected future climate change in the lake michigan region, J. Great Lakes Res., 36, Supplement 2, 33-50, 2010.

Chiew, F. H. S.: Estimation of rainfall elasticity of streamflow in australia, Hydrol. Sci. J., 51, 613-625, doi:10.1623/hysj.51.4.613, 2006.

Chiew, F. H. S., Whetton, P. H., McMahon, T. A., and Pittock, A. B.: Simulation of the impacts of climate change on runoff and soil moisture in australian catchments, J. Hydrol., 167, 121-147, doi:10.1016/0022-1694(94)02649-V, 1995.

Charles, S. P., Bari, M. A., Kitsios, A., and Bates, B. C.: Effect of $\mathrm{gcm}$ bias on downscaled precipitation and runoff projections for the serpentine catchment, Western Australia, Int. J. Climatol., 27, 1673-1690, doi:10.1002/joc.1508, 2007.

Christensen, N. S. and Lettenmaier, D. P.: A multimodel ensemble approach to assessment of climate change impacts on the hydrology and water resources of the Colorado River Basin, Hydrol. Earth Syst. Sci., 11, 1417-1434, doi:10.5194/hess-11-14172007, 2007.

Delworth, T. L., Broccoli, A. J., Rosati, A., Stouffer, R. J., Balaji, V., Beesley, J. A., Cooke, W. F., Dixon, K. W., Dunne, J., Dunne, K. A., Durachta, J. W., Findell, K. L., Ginoux, P., Gnanadesikan, A., Gordon, C. T., Griffies, S. M., Gudgel, R., Harrison, M. J., Held, I. M., Hemler, R. S., Horowitz, L. W., Klein, S. A., Knutson, T. R., Kushner, P. J., Langenhorst, A. R., Lee, H. C., Lin, S. J., Lu, 
J., Malyshev, S. L., Milly, P. C. D., Ramaswamy, V., Russell, J., Schwarzkopf, M. D., Shevliakova, E., Sirutis, J. J., Spelman, M. J., Stern, W. F., Winton, M., Wittenberg, A. T., Wyman, B., Zeng, F., and Zhang, R.: GFDL's CM2 global coupled climate models. Part I: Formulation and simulation characteristics, J. Climate, 19, 643-674, 2006.

Department of Water (DoW): Water solutions, winter'08, Perth, Western Australia, 9 pp., 2008.

Department of Water (DoW): Hydrological and nutrient modelling of the Peel- Harvey catchment, Water science technical series, Report no. WST33, Perth, Western Australia, 250 pp., 2011.

Department of Water (DoW): The effect of climate change on streamflow in south-west Western Australia: projections for 2050, Surface water hydrology series, Report no. HY34, Perth, Western Australia, 68 pp., 2010.

Dibike, Y. B. and Coulibaly, P.: Hydrologic impact of climate change in the Saguenay watershed: comparison of downscaling methods and hydrologic models, J. Hydrol., 307, 145-163, doi:10.1016/j.jhydrol.2004.10.012, 2005.

Flato, G. M.: The Third Generation Coupled Global Climate Model (CGCM3) (and included links to the description of the AGCM3 atmospheric model), available at: http://www.cccma.bc.ec.gc.ca/ models/cgem2.shtml, 2005.

Fowler H. J. and Wilby, R. L.: Beyond the downscaling comparison study, Int. J. Climatol., 27, 1543-1545, doi:10.1002/joc.1616, 2007.

Frederiksen, C. S., Frederiksen, J. S., Sisson, J. M., and Osbrough, S. L.: Changes and projections in australian winter rainfall and circulation: Anthropogenic forcing and internal variability, Int. J. Clim. Change, 2, 143-162, 2011a.

Frederiksen, C. S., Frederiksen, J. S., Sisson, J. M., and Osbrough, S. L.: Australian winter circulation and rainfall changes and projections, Int. J. Clim. Change, 3, 170-188, doi:10.1108/17568691111129002, $2011 \mathrm{~b}$.

Frederiksen, J. S. and Frederiksen, C. S.: Interdecadal changes in southern hemisphere winter storm track modes, Tellus A, 59, 599-617, doi:10.1111/j.1600-0870.2007.00264.x, 2007.

Frederiksen, J. S., Frederiksen, C. S., Osbrough, S. L., and Sisson, J. M.: Changes in southern hemisphere rainfall, circulation and weather systems, in: Proceedings of the 19th International Congress on Modelling and Simulation, Modelling and Simulation Society of Australia and New Zealand, Perth, Australia, 12-16 December 2011, 2712-2718, 2011c.

Fu, G., Charles, S. P., and Chiew, F. H. A two-parameter climate elasticity of streamflow index to assess climate change effects on annual streamflow, Water Resour. Res., 43, W11419, doi:10.1029/2007WR005890, 2007.

Fujihara, Y., Tanaka, K., Watanabe, T., Nagano, T., and Kojiri, T.: Assessing the impacts of climate change on the water resources of the seyhan river basin in turkey: Use of dynamically downscaled data for hydrologic simulations, J. Hydrol., 353, 33-48, 2008.

Gordon, H. B., Rotstayn, L. D., McGregor, J. L., Dix, M. R., Kowalczyk, E.A., O'Farrell, S. P., Waterman, L. J., Hirst, A. C., Wilson, S. G., Collier, M. A., Watterson, I. G., and Elliott, T. I.: The CSIRO Mk3 Climate System Model, CSIRO Atmospheric Research Technical Paper No. 60, CSIRO. Division of Atmospheric Research, Victoria, Australia, 130 pp., 2002.
Gordon, H. B., O’Farrell, S. P., Collier, M. A., Dix, M. R., Rotstayn, L. D., Kowalczyk, E. A., Hirst, T., and Watterson, I. G.: The CSIRO Mk3.5 Climate Model, CAWCR Technical Report No. 021, The Centre for Australian Weather and Climate Research, Australia, 2010.

Hughes, D. A., Kingston, D. G., and Todd, M. C.: Uncertainty in water resources availability in the Okavango River basin as a result of climate change, Hydrol. Earth Syst. Sci., 15, 931-941, doi:10.5194/hess-15-931-2011, 2011.

Indian Ocean Climate Initiative (IOCI): Climate Variability and Change in South West Western Australia, Technical Report, Indian Ocean Climate Initiative Panel, Perth, Australia, 34 pp., 2002.

Intergovernmental Panel on Climate Change (IPCC): Special report on emission scenarios, Cambridge University Press, UK., 570 pp., 2000.

Intergovernmental Panel on Climate Change (IPCC): Climate change 2001: Impacts, adaptation, and vulnerability, contribution of working group ii to the third assessment report of the intergovernmental panel on climate change, summary for policymakers, Cambridge University Press, Cambridge CB2 2RU, UK, 17 pp., 2001.

Intergovernmental Panel on Climate Change (IPCC): Climate change 2007: Impacts, adaptation, and vulnerability: Working Group II contribution to the Intergovernmental Panel on Climate Change Fourth Assessment Report, Summary for Policymakers, Cambridge University Presss, Cambridge, UK, 7-22, 2007.

Islam, S. A., Bari, M., and Anwar, A. H. M. F.: Assessment of hydrologic impact of climate change on Ord river catchment of Western Australia for water resources planning: A multi-model ensemble approach, in: Proceedings of the 19th International Congress on Modelling and Simulation, Perth, Western Australia, 12-16 December 2011, 3587-3593, 2011.

Joyce, L. R.: The hydrologic impacts of climate change and variability in the Murray Hotham catchment, Western Australia, B.Sc. thesis, School of Environmental Systems Engineering, The University of Western Australia, Perth, Western Australia, 125 pp., 2007.

Jones, D. A., Wang, W., and Fawcett, R.: High-quality spatial climate data-sets for Australia, Aust. Meteorol. Oceanogr. J., 58, 233-248, 2009.

Jungclaus, J. H., Botzet, M., Haak, H., Keenlyside, N., Luo, J.J., Latif, M., Marotzke, J., Mikolajewicz, U., and Roeckner, E.: Ocean Circulation and Tropical Variability in the Coupled Model ECHAM5/MPI-OM, J. Climate, 19, 3952-3972, 2006.

K-1 model developers: K-1 coupled model (MIROC) description, K-1 technical report, 1, edited by: Hasumi, H. and Emori, S., Center for Climate System Research, University of Tokyo, 34 pp., 2004.

Kitsios, A., Bari, M. A., and Charles, S. P.: Projected impacts of climate change on the Serpentine catchment, Downscaling from multiple General Circulation Models, Report No.WRT 36, Department of Water, Perth, Western Australia, 98 pp., 2009.

Kundzewicz, Z. W., Mata, L. J., Arnell, N. W., Döll, P., Kabat, P., Jiménez, B., Miller, K. A., Oki, T., Sen, Z., and Shiklomanov, I. A.: Freshwater resources and their management. Climate Change 2007: Impacts, Adaptation and Vulnerability. Contribution of Working Group II to the Fourth Assessment Report of the Intergovernmental Panel on Climate Change, edited by: Parry, M. L., 
Canziani, O. F., Palutikof, J. P., van der Linden, P. J., and Hanson, C. E., Cambridge University Press, Cambridge, UK, 173-210, 2007.

Li, Y., Cai, W., and Campbell, E. P.: Statistical modeling of extreme rainfall in southwest western australia, J. Climate, 18, 852-863, 2005

Mahat, V. and Anderson, A.: Impacts of climate and catastrophic forest changes on streamflow and water balance in a mountainous headwater stream in Southern Alberta, Hydrol. Earth Syst. Sci., 17, 4941-4956, doi:10.5194/hess-17-4941-2013, 2013.

Marti O., P. B., J. Bellier, R. Benshila, S. Bony, P. Brockmann, P. Cadule, A. Caubel,, S. Denvil, J.-L. D., L. Fairhead, M.-A. Filiberti, M.-A. Foujols, T. Fichefet,, P. Friedlingstein, H. G., J.-Y. Grandpeix, F. Hourdin, G. Krinner, C. Lévy, G. Madec,, and I. Musat, N. d. N., J. Polcher and C. Talandier: The new IPSL climate system model: IPSL-CM4. Note du Pôle de Modélisation no. 26, Institut Pierre Simon Laplace des Sciences de l'Environnement Global, IPSL Global Climate Modeling Group, 2006.

Mayer, X. M., Ruprecht, J. K., and Bari, M. A.: Stream salinity status and trends in south west Western Australia, salinity and land use impacts series, vol. 38, Department of Environment, Perth, Western Australia, 188, 2005.

Merritt, W. S., Alila, Y., Barton, M., Taylor, B., Cohen, S., and Neilsen, D.: Hydrologic response to scenarios of climate change in sub watersheds of the Okanagan basin, British Columbia, J. Hydrol., 326, 79-108, 2006.

Miller, W. A. and Cunge, J. A.: Simplified equations of unsteady flow, in: Unsteady Flow in Open Channels, edited by: Mahmood, K., and Yevjevich, V., Water Resources Publications, Fort Collins, USA, 183-257, 1975.

Nóbrega, M. T., Collischonn, W., Tucci, C. E. M., and Paz, A. R.: Uncertainty in climate change impacts on water resources in the rio grande basin, brazil, Hydrol. Earth Syst. Sci., 15, 585-595, doi:10.5194/hess-15-585-2011, 2011.

Nicholls, N.: Detecting, understanding and attributing climate change. A background report on research priorities prepared for the Australian greenhouse office, Australian Greenhouse Office, Canberra, Australia, 26 pp., 2007.

Pen, L. J. and Hutchison, J.: Managing Our Rivers: A Guide to the Nature and Management of the Streams of South-West Western Australia, Water and Rivers Commission, 382 pp., 1999.

Petrone, K. C., Hughes, J. D., Van Niel, T. G., and Silberstein, R. P.: Streamflow decline in southwestern australia, 1950-2008, Geophys. Res. Lett., 37, L11401, doi:10.1029/2010GL043102, 2010.

Public Works Department (P. W. D.): Streamflow records of Western Australia to 1982, Water Resources Branch, Public Works Department, Perth, Western Australia, Volume 2-Basins 613617,1984

Ritchie, J. W., Zammit, C., and Beal, D.: Can seasonal climate forecasting assist in catchment water management decision-making?: A case study of the Border Rivers catchment in Australia, Agr. Ecosyst. Environ., 104, 553-565, 2004.

Ruprecht, J. K., Li, Y., Campbell, E., Hope, P.: How Extreme SouthWest Rainfalls Have Changed, Climate Note 6/05, Perth, Western Australia, Indian Ocean Climate Initiative, 2, 2005.

Russell, G. L., Miller, J. R., and Rind, D.: A coupled atmosphere ocean model for transient climate change studies, Atmos. Ocean, 33, 683-730, 1995.
Russell, G. L., Miller, J. R., Rind, D., Ruedy, R. A., Schmidt, G. A., and Sheth, S.: Comparison of model and observed regional temperature changes during the past 40 years, J. Geophys. Res., 105, 14891-14898, 2000.

Risbey, J.: Dangerous climate change and water resources in Australia, Reg. Environ. Change, 11, 197-203, doi:10.1007/s10113010-0176-7, 2011.

Ryan, B. and Hope, P.: Indian Ocean Climate Initiative Stage 2: Report of Phase 2 Activity, Applying the methodological foundations of Stage 2 and updating regional interpretations from global climate modelling, Indian Ocean Climate Initiative Panel, Perth, Western Australia, 36 pp., 2006.

Salas-Mélia, D., Chauvin, F., Déqué, M., Douville, H., Guérémy, J. F., Marquet, P., Planton, S., Royer, J. F., and Tyteca, S.: Description and validation of the CNRM-CM3 global coupled model, CNRM working note 103, available at: http://www.cnrm.meteo. fr/scenario2004/paper_cm3.pdf, 2005.

Shrestha, R. R., Dibike, Y. B., and Prowse, T. D.: Modelling of climate-induced hydrologic changes in the lake winnipeg watershed, Journal of Great Lakes Research, 38, Supplement 3, 83-94, 2012.

Silberstein, R. P., Macfarlane, C. K., Petrone, K. C., Hughes, J. D., Dawes, W. R., Lambert, P., Li, M., Wallace, J. F., Ogden, G., Smart, N. F., and Aryal, S. K.: Stream flow and vegetation dynamics under a changing climate and forest management, Final Report to WA Water Foundation on Project 041-05, CSIRO Water for a Healthy Country National Research Flagship, Canberra, 2011.

Smith, I.: An assessment of recent trends in Australian rainfall, in: Australian Meteorological Magazine, Australian Bureau of Meteorology, 53, 163-173, 2004.

Smith, K., Boniecka, L., Bari, M. A., and Charles, S. P.: The impact of climate change on rainfall and stream flow in the Denmark river catchment, western Australia, surface water hydrology series, HY30, Department of Water, Perth, Western Australia, 58 pp., 2009.

Stern, H., Hoedt, G. D., and Ernst, J.: Objective Classification of Australian Climates, Aust. Meteorol. Magaz., 49, 87-96, 2000.

Surfleet, C. G., Tullos, D. e., Chang, H., and Jung, I.-W.: Selection of hydrologic modeling approaches for climate change assessment; a comparison of model scale and structures, J. Hydrol., 464-465, 233-248, doi:10.1016/j.jhydrol.2012.07.012, 2012.

Timbal, B., Fernandez, E., and Li, Z.: Generalization of a statistical downscaling model to provide local climate change projections for Australia, Environ. Model. Softw., 24, 341-358, doi:10.1016/j.envsoft.2008.07.007, 2009.

Water Corporation: Water forever: directions for our water future: draft plan/Water Corporation, Water Corporation, Perth, Western Australia, 2009.

Western Australia (WA): Securing our water future: a state water strategy for Western Australia, Government of Western Australia, Perth, Western Australia, 64 pp., 2003.

Wilby, R. L. and Harris, I.: A framework for assessing uncertainties in climate change impacts: Low-flow scenarios for the river thames, UK, Water Resour. Res., 42, W02419, doi:10.1029/2005wr004065, 2006.

Wood, E. F., Lettenmaier, D. P., and Zartarian, V. G.: A LandSurface Hydrology Parameterization With Subgrid Variability 
for General Circulation Models, J. Geophys. Res., 97, 27172728, doi:10.1029/91JD01786, 1992.

Yukimoto, S., Noda, A., Kitoh A., Sugi, M., Kitamura, Y., Hosaka, M., Shibata, K., Maeda, S., and Uchiyama, T.: The New Meteorological Research Institute Coupled GCM (MRI-CGCM2), Model Climate and Variability, Pap. Meteorol. Geophys., 51, 4788, 2001.
Zorita, E. and Storch, H. V.: The Analog Method as a simple statistical downscaling technique: comparison with more complicated methods, J. Climate, 12, 2474-2489, 1999. 